\title{
Edible Cyanobacterial Genus Arthrospira: Actual State of the Art in Cultivation Methods, Genetics, and Application in Medicine
}

\author{
Magda A. Furmaniak ${ }^{1 \dagger}$, Agnieszka E. Misztak ${ }^{2 \dagger}$, Martyna D. Franczuk ${ }^{1 \dagger}$, Annick Wilmotte ${ }^{3}$, \\ Małgorzata Waleron ${ }^{2}$ and Krzysztof F. Waleron ${ }^{1 *}$ \\ ${ }^{1}$ Chair and Department of Pharmaceutical Microbiology, Medical University of Gdańsk, Gdańsk, Poland, ${ }^{2}$ Department of \\ Biotechnology, Intercollegiate Faculty of Biotechnology of University of Gdańsk and Medical University of Gdańsk, Gdańsk, \\ Poland, ${ }^{3}$ InBios-Centre for Protein Engineering, Department of Life Sciences, University of Liège, Liège, Belgium
}

\section{OPEN ACCESS}

Edited by:

Télesphore Sime-Ngando, Centre National de la Recherche

Scientifique (CNRS), France

Reviewed by:

Dmitry A. Los,

Timiryazev Institute of Plant Physiology

(RAS), Russia

Pawan K. Dadheech,

Central University of Rajasthan, India

${ }^{*}$ Correspondence:

Krzysztof F. Waleron

krzysztof.waleron@gumed.edu.pl

${ }^{\dagger}$ These authors have contributed equally to this work

Specialty section:

This article was submitted to

Aquatic Microbiology,

a section of the journal

Frontiers in Microbiology

Received: 28 July 2017 Accepted: 06 December 2017 Published: 18 December 2017

Citation:

Furmaniak MA, Misztak $A E$, Franczuk MD, Wilmotte A, Waleron M and Waleron KF (2017) Edible Cyanobacterial Genus Arthrospira:

Actual State of the Art in Cultivation Methods, Genetics, and Application in Medicine. Front. Microbiol. 8:2541. doi: 10.3389/fmicb.2017.02541
The cyanobacterial genus Arthrospira appears very conserved and has been divided into five main genetic clusters on the basis of molecular taxonomy markers. Genetic studies of seven Arthrospira strains, including genome sequencing, have enabled a better understanding of those photosynthetic prokaryotes. Even though genetic manipulations have not yet been performed with success, many genomic and proteomic features such as stress adaptation, nitrogen fixation, or biofuel production have been characterized. Many of above-mentioned studies aimed to optimize the cultivation conditions. Factors like the light intensity and quality, the nitrogen source, or different modes of growth (auto-, hetero-, or mixotrophic) have been studied in detail. The scaling-up of the biomass production using photobioreactors, either closed or open, was also investigated to increase the production of useful compounds. The richness of nutrients contained in the genus Arthrospira can be used for promising applications in the biomedical domain. Ingredients such as the calcium spirulan, immulina, C-phycocyanin, and $\gamma$-linolenic acid (GLA) show a strong biological activity. Recently, its use in the fight against cancer cells was documented in many publications. The health-promoting action of "Spirulina" has been demonstrated in the case of cardiovascular diseases and age-related conditions. Some compounds also have potent immunomodulatory properties, promoting the growth of beneficial gut microflora, acting as antimicrobial and antiviral. Products derived from Arthrospira were shown to successfully replace biomaterial scaffolds in regenerative medicine. Supplementation with the cyanobacterium also improves the health of livestock and quality of the products of animal origin. They were also used in cosmetic preparations.

Keywords: Arthrospira, Spirulina, genetics, biotechnology, medical application, cyanobacteria

\section{BACKGROUND}

Arthrospira is an extremophilic pioneer organism with optimal growth temperatures around $35^{\circ} \mathrm{C}$. Therefore, it is most abundant in tropical and subtropical regions. Ancient civilizations like the Aztecs were first to recognize the nutritional value of these organisms. Inhabitants of Europe came into contact with Arthrospira during the colonization of America in the sixteenth century, 
hence the first references made at that time (Ciferri, 1983). Nowadays, it is still harvested, dried, and consumed by the Kanembu tribe in Chad (Africa) and called "dihé." Scientific interest in Arthrospira species was boosted after the first chemical analyses of biomass from dihé in late 1960's (Ciferri, 1983). Subsequently, it started to be extensively studied due to its nutritional properties.

Arthrospira is a genus of the cyanobacterial phylum. This multicellular organism is characterized by open helical trichomes that give it a typical morphology and it has a recognized biotechnological potential (Figure 1). The oldest reference for the consumption of Arthrospira dates back from the sixteenth century, but its use could even be more ancient (Miklaszewska et al., 2008b). Since the genus was rediscovered in Chad and Mexico in the 1950's, the interest for Arthrospira applications has grown and diversified from nutrition to health, and biotechnology. However, until now, genetic engineering has turned out to be impossible due to the lack of proper technology. Fortunately, recent technological advances in the sequencing of entire genomes and genetic studies have shed a new light on its basic molecular biology as well as cyanobacterial genetics.

One of the most promising projects including Arthrospira is the Micro-Ecological Life Support System Alternative (MELiSSA) that aims to create an artificial ecosystem to recycle waste and oxygen for long-duration space expeditions (Gòdia et al., 2002). This multinational project consists of four compartments utilizing microbial consortia (compartment 1) or defined microorganisms (compartments 2-4). The four compartments form a closed loop that is fed by the wastes from the human crew and vegetable left-overs to recycle them. The effluent from one compartment becomes the influent of the next one. The last compartment is responsible for the removal of $\mathrm{CO}_{2}$ from atmosphere, water recycling, and production of food and oxygen. It includes both higher plants and the Arthrospira strain PCC8005 (Hendrickx et al., 2006; Badri et al., 2015).

The last comprehensive overview dedicated to Arthrospira was published in 1997 (Vonshak). As a result of the scientific interest in this taxon, a large amount of data has been generated (Figure 2). Here, we summarize the information crucial for the understanding of the modern biology and perspectives concerning this genus.

\section{GENETICS}

The DNA content of the dry biomass of Arthrospira varies from 0.6 to $1 \%$, which is similar to other unicellular cyanobacteria, but significantly lower than other bacteria or yeast (4-10\%). The guanidine plus cytosine content is in the range 44-45 mol\%. The average size of the Arthrospira genomes is 6.1 Mbp (Ciferri, 1983; Fujisawa et al., 2010; Cheevadhanarak et al., 2012; Lefort et al., 2014). In addition, the biomass of Arthrospira is rich in substances such as polysaccharides and polyphenols that are very difficult to remove during the DNA isolation process (De Philippis and Vincenzini, 1998; Morin et al., 2010). Apart from the low content of nucleic acids in its dry biomass, Arthrospira genomes seem to lack non-chromosomal

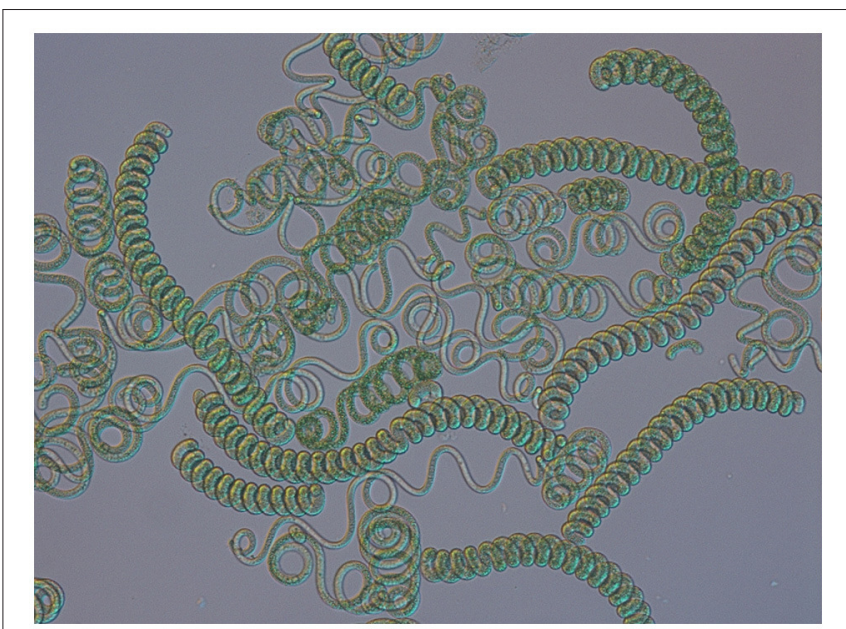

FIGURE 1 | Light microscopy of Arthrospira filaments from natural environment (magnification 200x).

DNA. The last report concerning the isolation of plasmid from Arthrospira was published in 1993 (Song et al., 1993), and has not been reproduced. These missing plasmids would have been indispensable tools for gene manipulation.

\section{Phylogenetics}

The commercial name of Arthrospira products-"Spirulina"causes a constant confusion. In 1932, Geitler has merged the genera Arthrospira and Spirulina (Geitler, 1932). The new name was Spirulina because this genus had been described by Turpin a few years before Stizenberger described Arthrospira (Vonshak, 1997). Research carried out in the last two decades showed that at ultrastructure and genetic (percentage of G+C, 16S rRNA gene sequence) level, Arthrospira and Spirulina were very distinct organisms (Herdman et al., 1979; Guglielmi et al., 1993; Nelissen et al., 1994). Chemotaxonomically, those two genera were also shown to be different, as the Arthrospira fatty acids profile included $\gamma$-linolenic acid (GLA), that is absent in Spirulina (Cohen and Vonshak, 1991). A phylogenetic study based on the $c p c A-c p c B$ locus revealed that the closest relative of the Arthrospira genus is Planktothrix and that it is not related with Spirulina (Manen and Falquet, 2002). The study by Shih et al. (2013) presents an analysis of 74 publicly available and 54 newly sequenced cyanobacterial genomes, including 4 belonging to Arthrospira. The strains used in this study were diverse at the phylogenetic and phenotypical level. According to Shih et al. (2013), Lyngbya was the closest relative of Arthrospira based on 16S rRNA sequence, however, the Planktothrix genus was not included in this database.

The Arthrospira strains show high morphological similarities but also genetic homogeneity. This complicates their taxonomy, that is the subject of a few publications (Desikachary and Jeeji Bai, 1992; Komárek and Anagnostidis, 2005). At the morphological level, scientists have observed spontaneous changes from a spiral to a straight morphology in Arthrospira trichomes, dependent 


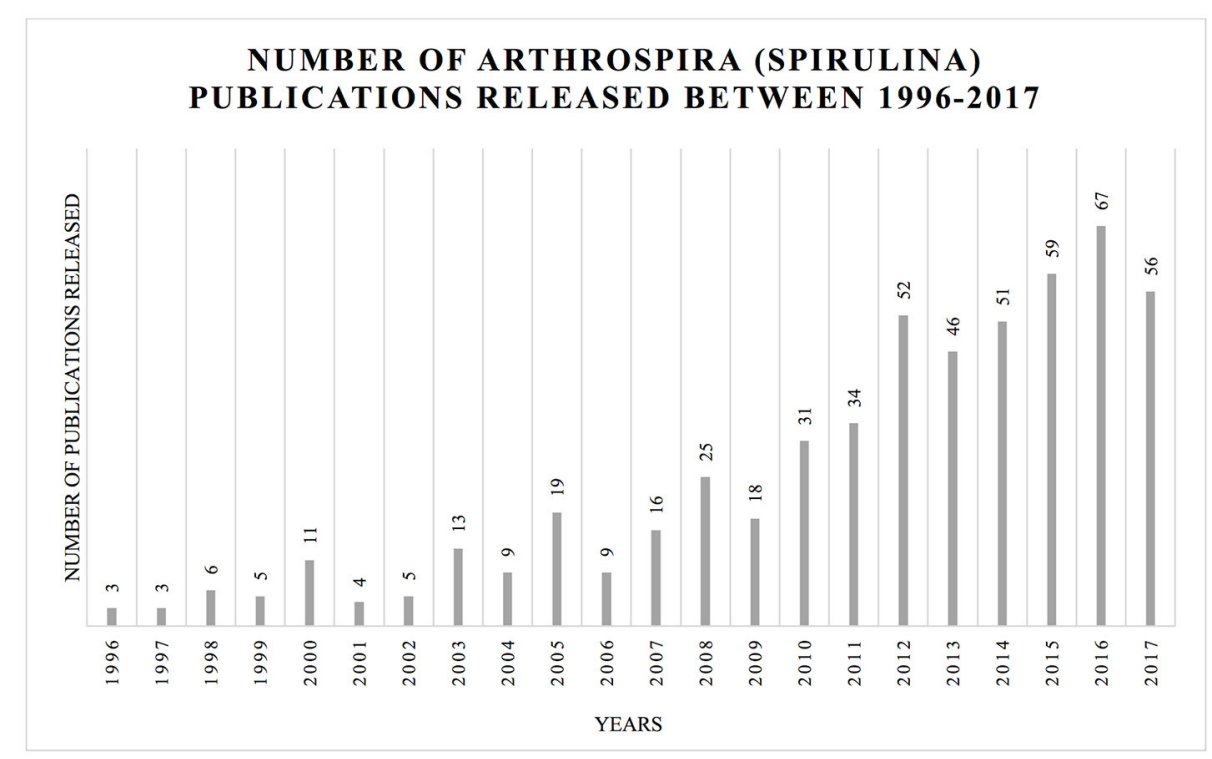

FIGURE 2 | Increasing number of publications in the topic of Arthrospira (Spirulina) between 1996 and October 2017. The histogram illustrates the number of hits for Arthrospira (Spirulina) using Web of Science (https://apps.webofknowledge.com) platform using respective keywords: TOPIC: (Arthrospira) AND TOPIC: (Spirulina platensis); Timpespan: All years.

on cultivation conditions (Desikachary and Jeeji Bai, 1996; Tomaselli, 1997; Muhling et al., 2005; Wang and Zhao, 2005).

The ITS (Internally Transcribed Sequence) is a non-functional spacer situated between structural rRNA genes in the precursor transcript, and is subjected to less conservation pressures than the structural genes. It is used in molecular taxonomy to distinguish different species (Taton et al., 2003). The ITS sequences show large variations in length and sequence between species, and they are easier to amplify because the rRNA operons are present in several copies. Based on ITS sequences and ARDRA fingerprinting analysis, 54 strains of the Arthrospira genus from four continents have been divided into five clusters grouped in two main genetic variants: IA, IB, IIA, IIB, IIA/IIB (Scheldeman et al., 1999; Baurain et al., 2002) and to which the new genetic variant III was later added (Comte et al., 2013). A study conducted by Manen and Falquet (2002) on the cpcBA locus reaffirmed that Arthrospira genus consists of three genetically clustered lineages. However, there was little overlap between the studied strains and the congruence between lineages observed on the basis of the different markers could not be assessed.

The usefulness of the cpcBA-IGS locus and ITS in Arthrospira phylogeny was presented by Dadheech et al. (2010). Thirty-three Arthrospira strains collected from North America, Africa and India were analyzed in comparison to 53 known Arthrospira strains using morphological traits and molecular phylogeny. Phylogenetic trees obtained in this study, one based on $c p c \mathrm{BA}-$ IGS and the second on the ITS region, were divided into two clusters-cluster I and cluster II, which is congruent with findings of Baurain et al. (2002) and Manen and Falquet (2002). Interestingly, the phylogenetic cluster division was related to Arthospira strains' origin. Strains in cluster I were mainly collected from Mexico, USA, or Peru, whereas in cluster II, they were collected from China, India, Kenya, or Chad, suggesting different evolutionary tracks of the two clusters.

\section{Transformation}

The first attempt to build an Arthrospira DNA library was made by Kawata et al. (1998), with a method based on sonication, usage of TaqDNA polymerase, and ligation with a TA vector (Kawata et al., 1998). Further studies tested transformation methods based on electroporation. The method proposed by Kawata et al. suggested the use of a few elements (1) electroporation procedure, (2) elements of transposition system: natural Tn5 transposon and transposase, (3) cation liposome complexes, (4) and finally the cat reporter gene with chloramphenicol acetyltransferase (Toyomizu et al., 2001a; Kawata et al., 2004). However, this protocol was not reproduced. Recent study of Jeamton et al. (2017), resulted in an efficient and stable transformation of Arthrospira platenis C1. This protocol was also based on electroporation, but its novelty was the use of a type I restriction-modification systems inhibitor and liposomes to protect the DNA.

\section{DNA Libraries, Mutagenesis, and Restriction-Modification Systems}

Since 1981, various Arthrospira mutagenesis studies have been performed, mainly by Riccardi et al. NGT (nitrosoguanidine) was used as mutagenic agent, and resulted in A. platensis mutants resistant to: 5-fluorotryptophan, $\beta$-2-thienylalanine, ethionine, p-fluorophenylalanine, or azetidine-2-carboxylic acid (Riccardi et al., 1981, 1982). These mutants have been divided into two groups: mutants resistant to more than one analog, and mutants resistant to only one analog, both overproducing the corresponding amino acid. Researchers' attention focused on 
proline overproducing mutants, belonging to the second group. Some studies suggested that proline may be responsible for osmoregulation in blue-green algae (Gilles and Gilles-Baillien, 1985; Singh et al., 1996). Growth tests showed that, while control cultures' growth decreased with increasing $\mathrm{NaCl}$ concentration, proline-overproducing mutants' growth remained constant. Singh et al. (1996) revealed that a mutant strain of Nostoc muscorum with proline overaccumulation presented enhanced salinity tolerance. This suggests that simple genetic approaches, like point mutations, could be a solution for culture growth problems (Vonshak, 1997).

In 2008, via UV mutagenesis, Choi et al. obtained a mutant strain of A. platensis PCC 9108 that was able to grow mixotrophically in a SOT medium with glucose addition. The study revealed that the mutant biomass growth was significantly higher than a wild-type Arthrospira. Furthermore, the $\gamma$-linolenic acid (GLA) content (increasing with a higher dose of glucose in the medium) was two-fold higher in autotrophic culture and three-fold higher in mixotrophic one in comparison to the wild type. This suggests that the mutant strain possesses the ability to easier assimilate and metabolize glucose and presents an increased production of GLA (Choi et al., 2008).

Genetic studies have revealed the activity of restrictionmodification (RM) systems in filamentous cyanobacteria (Zhao et al., 2006). Those bacterial systems protect cells from exogenous DNA. They consist of two enzymes: a restriction endonuclease, cutting the DNA at a specific site, and a methyltransferase, adding a methyl group to cytosine or adenine in the autochtonous DNA strand, preventing it from being cut. Restriction-modification systems are important in genetic studies, molecular cloning and are a perfect model for examining DNA-protein interactions (Wilson, 1991; Pingoud and Jeltsch, 2001; Waleron et al., 2006). In the study of Zhao et al. (2006), Synechocystis, Synechococcus Prochlorococcus, Anabaena, Nostoc, Spirulina, and Trichodesmium strains were examined in silico, using the RM gene set obtained from CyanoBase. The (BLAST)P and TBLASTN tools were used to obtain 30 putative RM genes, mostly type I RM systems. Additionally, gene expression profiles for "Spirulina" methyltransferases were characterized by the RTPCR method (Zhao et al., 2006).

A recent study of Shiraishi and Tabuse (2013) revealed the presence of a new RM system in the A. platensis NIES-39 genome, named AplI. The NIES39_K04640 gene, a putative type II restriction enzyme, showed an endonuclease activity specific at the $5^{\prime}$-CTGCAG-3' sequence.

\section{Genome Studies}

Hitherto seven Arthrospira genomes have been fully sequenced: Arthrospira sp. PCC8005, A. platensis NIES-39, A. platensis C1, A. maxima CS-328, A. platensis Paraca P0 (WGS), A. platensis YZ, and Arthrospira sp. TJSD091 (Fujisawa et al., 2010; Janssen et al., 2010; Carrieri et al., 2011; Cheevadhanarak et al., 2012; Lefort et al., 2014; Dong et al., 2015) (Table 1). According to the statistical comparisons (Cheevadhanarak et al., 2012), genome sizes of the Arthrospira strains range from $4.9 \mathrm{Mbp}$ (A. platensis Paraca P0) to $6.8 \mathrm{Mbp}$ (A. platensis NIES-39). The genome is organized as a single, circular chromosome and cells contain no known plasmid DNA. The total gene numbers vary from 5,401 to 6,676 , and the percentage of protein-coding genes reaches up to $99 \%$ (Fujisawa et al., 2010; Janssen et al., 2010; Carrieri et al., 2011; Cheevadhanarak et al., 2012; Lefort et al., 2014; Dong et al., 2015).

All genomes contain highly interspersed repetitive sequences (reaching up to $9 \%$ of the genomes), including group II introns, phage-like sequences, insertion elements and, on average, six to 13 CRISPRs (Clustered Regularly Interspaced Short Palindromic Repeats). Together with RM systems, they compose a cellular defense system, which is a major barrier in the transformation of cyanobacterial cells (Fujisawa et al., 2010; Janssen et al., 2010; Cheevadhanarak et al., 2012; Lefort et al., 2014).

\section{Phages}

Little is known about Arthrospira cyanophages. The first report about a virus infecting $A$. platensis was published by Jacquet and collaborators in 2013. The discovered phage was isolated from commercial culture ponds located in the South of France. On the basis of molecular and morphological characteristics, it was thought to be a member of the cyanopodovirus group, but finally, it appeared to be a very narrow host specific virus (Jacquet et al., 2013). Kaggwa et al. (2013) and Peduzzi et al. (2014) noticed morphological changes in Arthrospira fusiformis from African saline lakes connected with cyanophage infections. Infected cells formed long, narrow coiled filaments. Lysis and sudden breakdown in A. fusiformis biomass, which is a main food supply for flamingos, may cause a periodical decrease in their populations in African lakes (Peduzzi et al., 2014).

\section{Gas Vesicles}

In various aquatic prokaryotes, including Arthrospira, gas vacuoles are present and provide buoyancy to the cells. In the Arthrospira genus, gas vesicle clusters are dispersed throughout the cells, although their occurrence is dependent on culture conditions and may be lost as a result of mutations (Castenholz et al., 2001). Walsby (1994) revealed that there are two main gas vesicle proteins, GvpA, the small rib protein, and GvpC, the large outer surface protein. The most characteristic feature of GvpC protein is the presence of a highly conserved motif of 33 amino acid residues, forming tandem repeats. Miklaszewska et al. (2012) have proposed the following structure for the gvp operon: $g v p A 1$ $g v p C 1-g v p A 2-g v p C 2-g v p A 3-g v p C 3-g v p N$, which was identical in five analyzed Arthrospira strains. Although the operon could not be assembled during genome analysis, its structure could be determined by gene cloning. Additionally, the comparison of the gvp genes sequence between five Arthrospira strains (PCC 8005, PCC 7345, PCC 9108, PCC 9444, Moz 2.1) revealed the presence of polymorphic positions characteristic for different genetic clusters (I and II).

\section{Stress Adaptation}

Members of the Arthrospira genus are known from their resistance to different environmental conditions: high temperature, alkaline $\mathrm{pH}$, high salt concentration. Genome studies revealed potential genes responsible for the adaptation capacity of Arthrospira. Nap-A type $\mathrm{Na}+/ \mathrm{H}+$ antiporters of 
TABLE 1 | Summary of statistics of available on NCBI Arthrospira genomes data.

\begin{tabular}{|c|c|c|c|c|c|c|c|}
\hline Strain & $\begin{array}{c}\text { Arthrospira } \\
\text { maxima CS-328 }\end{array}$ & $\begin{array}{l}\text { Arthrospira } \\
\text { platensis C1 }\end{array}$ & $\begin{array}{c}\text { Arthrospira platensis } \\
\text { NIES-39 }\end{array}$ & $\begin{array}{c}\text { Arthrospira platensis } \\
\text { str. Paraca }\end{array}$ & $\begin{array}{l}\text { Arthrospira } \\
\text { platensis YZ }\end{array}$ & $\begin{array}{l}\text { Arthrospira sp. } \\
\text { PCC8005 }\end{array}$ & $\begin{array}{c}\text { Arthrospira sp. } \\
\text { TJSD091 }\end{array}$ \\
\hline Number of scaffolds & 129 & 1 & 1 & 268 & 1 & 1 & 359 \\
\hline Number of contigs & 129 & 63 & 18 & 208 & 10 & 6 & 296 \\
\hline Largest contig & 324197 & 799912 & 870292 & 297520 & 2167980 & 2117149 & 164291 \\
\hline Total length & 6003314 & 6089210 & 6788435 & 6501886 & 6520772 & 6228153 & 5978827 \\
\hline GC (\%) & 44.76 & 44.68 & 44.27 & 44.3 & 44.19 & 44.73 & 44.75 \\
\hline N50 & 92573 & 206210 & 619347 & 72660 & 1054592 & 1412831 & 50394 \\
\hline $\begin{array}{l}\text { ITS cluster (after } \\
\text { Baurain et al., 2002) }\end{array}$ & I.A & I.A & $\| . A$ & $\| . A$ & $\| . A$ & I.B & I.A \\
\hline Sequencing method & n.a. & $\begin{array}{l}\text { Sanger/454 GS } \\
\text { FLX Titanium }\end{array}$ & ABI 3730 & Illumina HiSeq & $\begin{array}{c}\text { ABI 3730/lllumina } \\
\text { GAllx }\end{array}$ & n.a. & Illumina HiSeq \\
\hline coverage & n.a. & $28 x$ & $11 x$ & $36 x$ & $86 x$ & n.a. & $130 x$ \\
\hline
\end{tabular}

the membrane transporter family are known to be involved in salt tolerance at alkaline $\mathrm{pH}$ in several cyanobacterial species. Accumulation of bicarbonate in the cytoplasm additionally influences photosynthesis in high $\mathrm{pH}$ conditions. Homologs of these antiporters have been found in all Arthrospira genomes. A. platensis NIES-39 genome possesses seven genes encoding putative $\mathrm{Na}+/ \mathrm{H}+$ antiporters, as well as two sets of genes for $\mathrm{CO}_{2}$ uptake (NDH-1) (Furrer et al., 2007; Fujisawa et al., 2010).

Another strategy for the tolerance to high salinity, in addition to ion transport, is the accumulation of compatible solutes in cyanobacterial cells. Compatible solutes are organic, highly water soluble compounds, that counterbalance the osmotic potential and maintain the cellular turgor. Those molecules also exhibit protective effects toward some sensitive macromolecules, what enhances their role in salinity stress tolerance. The genes responsible for the biosynthesis of three compatible solutes (trehalose, glucosylglycerol, glucosylglycerate) were detected by Hagemann, 2010, 2013) in four Arthrospira genomes (Arthrospira maxima CS-328, Arthrospira sp. PCC8005, A. platensis NIES-39, A. platensis Paraca P0). In A. platensis NIES-39 and Arthrospira sp. PCC8005, the trehalose biosynthesis pathway seems incomplete (Hagemann, 2010, 2013).

\section{Nitrogen Fixing and Hydrogen Production}

Arthrospira was originally described as a non-nitrogen fixing species, however, some genes responsible for heterocyst maturation (pat $U$, hetR, het $F$ ) and nitrogen fixation are conserved in all Arthrospira genomes. This fact suggests that heterocyst and trichome formation might be coupled (Fujisawa et al., 2010).

Analysis of A. platensis NIES-39 and Arthrospira sp. PCC8005 genomes revealed the presence of hydrogenase genes (hox and hyp loci). This suggests that Arthrospira is a potential organism for clean energy production (Fujisawa et al., 2010; Janssen et al., 2010). Indeed, Arthrospira strains are now being tested for hydrogen production (Juantorena et al., 2007; Raksajit et al., 2012).

Carrieri et al. (2011) have shown an increased autofermentation of the carbohydrates (glycogen and sugars) produced by the photosynthetic pathway under dark, anoxic conditions in A. maxima CS-328. By replacing potassium with sodium in cultivation buffers, these authors obtained high (67\% higher than in normal conditions) yields of hydrogen, acetate, and ethanol. Removal and blocking of a sodium ion gradient resulted in increased catabolism of intracellular carbohydrates by Arthrospira cells. Additionally, genome sequencing studies revealed the presence of e.g., homologs of P-type ATPase that extrude sodium at the expense of ATP hydrolysis; genes homologous to bicA that encode sodium-bicarbonate symport protein; genes encoding a Mrp complex that play a role in extruding sodium under anoxic conditions (Carrieri et al., 2011).

\section{Toxin Production}

Genome analyses of A. platensis $\mathrm{C} 1$ and A. platensis NIES-39 also revealed the absence of genes responsible for the biosynthesis of toxins: non-ribosomal peptide toxins, polyketide toxins, ureaderived toxin and others, what makes the Arthrospira genus safe for biomass and food production. However, genomic studies showed the presence of genes encoding proteins containing an RTX-motif, that is characteristic for hemolysins (Fujisawa et al., 2010; Cheevadhanarak et al., 2012), though toxicity analysis proved that Arthrospira is safe to consume (FDA, 2002). RTXmotif proteins are also thought to play a role in plant nodulation and cyanobacteria motility, which may explain their presence in Arthrospira genomes (Hoiczyk and Baumeister, 1997; Linhartová et al., 2010).

The first cyanobactin cluster described in the cyanobacterial phylum was the patellamide group of bactins. Cyanobactin gene cluster consists of at least few elements: a precursor peptide gene and two short conserved hypothetical proteins named by similarity to the canonical patellamide cluster (Donia and Schmidt, 2011). In the Arthrospira genus, the art gene cluster (arthrospiramide) shows the features typical for cyanobactins, except for the presence of additional precursor peptides and a transposase gene between $\operatorname{art} F$ and $\operatorname{art} G$. Although cyanobactins from Arthrospira genus encoded by the art gene cluster have been purified, their pharmacological properties should be further investigated (Donia and Schmidt, 2011). Based on a study of the 
$\mathrm{N}$-terminal gene phylogeny, arthrospiramide was classified into cluster VI within already identified cyanobactins (Martins et al., 2013).

\section{Proteomics and Transcriptomics}

The first proteomic study of Arthrospira in light/dark diurnal cycles based on shotgun proteomics has recently been published. Examination concerns Arthrospira sp. PCC8005 strain and is based on fractionation workflows methods: gel-free and gelbased protein/peptide, combined with Liquid ChromatographyTandem Mass Spectrometry (LC-MS/MS). Each of the methods provided a different number of identified proteins. Overall, the combined analysis resulted in the identification of 1,306 proteins. The researchers suggested that it represents a $21 \%$ coverage of the theoretical proteome of A. platensis PCC8005 (MatallanaSurget et al., 2014). Further study revealed that regulation of the 30 identified proteins differed during the light/dark growth transition. This effect was mainly observed for proteins related to Calvin cycle, photosynthesis, and translation processes. Genome studies indicated that Arthrospira contains the kai $A B C$ genes, responsible for controlling the circadian clock. Interestingly, only one biological replicate showed the presence of kai proteins, whereas an inference of gene regulation was impossible. The study revealed that kaiA gene maintains a periodic expression under constant light conditions and that the overall A. platensis responses to LD (light/dark) cycles were correlated with the Earth conditions. The researchers suggest that further studies are needed to maintain a suitable and efficient bioreactor for long-term manned missions in space (Matallana-Surget et al., 2014).

Another proteomic study of Arthrospira was focused on protein expression under salt stress (Wang et al., 2013). The strain A. platensis- $\mathrm{YZ}$ was grown under salt-stress conditions: $0.02,0.5,1.0 \mathrm{M} \mathrm{NaCl}$, and the protein expression patterns were compared. The study revealed that 114 proteins out of 141 were homologous to the ones in other Arthrospira strains (A. platensis Paraca and A. maxima CS-328), but the others were thought to originate from the other bacteria. The expression level of 29 genes responsible for salt-stress response was measured by qRT-PCR. The results showed that the transcription level of 11 genes remained up-regulated, and expressions of all 12 examined genes were consistent at their transcription and protein level. Proteins studied by Wang et al. (2013) were classified into 18 types according to their function (such as carbohydrate transport and metabolism, cell envelope biogenesis, post-translational modification or translation, ribosomal structure), and they were involved in 31 different metabolic pathways.

Huili et al. (2013) studied by proteomics the temperature response at 15,35 , and $45^{\circ} \mathrm{C}$ of $A$. platenis $\mathrm{YZ}$ strains. The expression of 122 proteins was significantly affected at different temperatures. In this study, the majority of the genes were homologous to those from other Arthrospira genomes (116 homologous genes out of 122 examined). Proteins showing different expression with changing temperatures appeared to be involved in different functions. This included the post-translational modification (e.g., chaperones), translation (e.g., ribosomal biogenesis), carbohydrate transport, energy metabolism (e.g., respiratory electron transport), and others that were classified in 14 different types depending on the functions by the COG database. Likewise, in the previous study of salt-stress (Wang et al., 2013), the transcription and translation levels of 26 proteins measured by qRT-PCR remained constant.

Transcriptome in different stress conditions have been studied e.g., N-limited stress (Deschoenmaeker et al., 2014; Depraetere et al., 2015), high temperature (Panyakampol et al., 2014), and sulfur stress (Kumerasan et al., 2017). Down-regulation of de novo protein synthesis under $\mathrm{N}$-limited stress has been revealed by Depraetere et al. (2015). Study of Panyakampol et al. (2014) suggest up-regulation of thermal-responsive genes helps the cells to remain in homeostasis during high-temperature conditions. Group of Kumerasan et al. (2017) observed that sulfur stress decreases level of pigments and reduces the biomass growth. Additionally, they revealed that Arthrospira was able to survive the stress due to expression changes of genes related with sulfur metabolism.

Majority of the mentioned transcriptomic studies were based on microarray assay, so it is relevant to mention that complete transcriptome of Arthrospira genus remains unavailable.

Due to the mass-scale character of commercial Arthrospira cultivation, understanding of the mechanisms that underlie responses to environmental changes is essential. In response to that, group of Senachak et al. (2015) developed an online platform, SpirPro, with integrated proteome and PPI database of A. platensis $\mathrm{C} 1$, publicly available on the web.

\section{CULTIVATION METHODS}

\section{Light Intensity}

Light, temperature, and nutrient availability are considered to be major limiting factors for Arthrospira growth in adequate culture media. Arthrospira, a photosynthetic organism, needs light as the main energy source and many studies were focused on light intensity effect on the increase in biomass production. In laboratory conditions, however, some discrepancies were observed concerning the most favorable light intensity for optimal biomass production. Zarrouk in his doctoral thesis determined an optimal photosynthetic photon flux (PPF) at 480$550 \mu \mathrm{mol} \mathrm{m}^{-2} \mathrm{~s}^{1}$. More recent studies report an optimal light intensity for maximal biomass production that varies between $37 \mu \mathrm{mol} \mathrm{m}{ }^{-2} \mathrm{~s}^{-1}$ (Kumar et al., 2011) and 150-200 $\mu \mathrm{mol}$ $\mathrm{m}^{-2} \mathrm{~s}^{-1}$ (Markou et al., 2012). Those values correspond to the light intensity of an overcast day and of a sunny day, respectively. These differences in reported values may be a result of using different sources of light and different strains of Arthrospira. However, at some point, photoinhibition, loss of photosynthetic capacity due to damage caused by photon flux, can be observed. Consequently, reduction of biomass production is observed (Vonshak, 1997). Arthrospira cultures grown in outdoor ponds at higher cell density providing selfshading or/and with net shading showed a lower reduction in the Fv/Fm ratio (parameter describing the maximal photochemical efficiency of PSII), that was helpful in maintaining suitable biomass productivity (Vonshak et al., 2014). This approach allowed to obtain a higher biomass yield by comparison to 
indoor production. Additionally, light intensity has been proven to have a linear effect on extracellular polymeric substances (EPS) production by Arthrospira. According to Trabelsi et al. (2009), a light intensity of $180 \mu \mathrm{mol} \mathrm{m} \mathrm{m}^{-2} \mathrm{~s}^{-1}$ and presumably higher values result in a significant increase of EPS production.

\section{Led Light of Different Colors}

Although fluorescent lamps seem to be the most popular light source for Arthrospira cultivation in laboratories, it can also be grown under illumination provided by different light sources like e.g., light emitting diode (LED). In a study, the effect of a mono-, di-, and polychromatic LED light (of average intensity $166 \mu \mathrm{mol} \mathrm{m} \mathrm{m}^{-2} \mathrm{~s}^{-1}$ ) on productivity and cell composition was determined. The greatest increase in biomass production was observed in cultures illuminated with red and pink light. Cultures illuminated with yellow and white LED light showed almost a two times lower productivity. The lowest increase in biomass production was observed under blue LED light. This difference in growth rate is probably a result of pink and red LED emitting in close proximity to chlorophylls $(435 / 676 \mathrm{~nm})$ and phycocyanin $(620 \mathrm{~nm})$ absorption peaks, while other colors emit at wavelengths relatively distant (Markou, 2014). Chen et al. (2010) and Wang et al. (2007) obtained similar results, while Ravelonandro et al. (2008) and Madhyastha and Vatsala (2007) described best biomass productivity under cultivation with green and blue light illumination. This contradiction probably is a result of using different light sources. It is also worth pointing that in many reports, the light sources' descriptions are neglected as only the irradiance level is provided, which may lead to bad reproducibility of the obtained results.

Changes in light color used for culture illumination also have an impact on cell composition. Cultures of A. platensis cultivated under different light colors showed no changes in carotenoid composition. However, blue LED illumination resulted in the highest content of, not only chlorophyll and phycocyanin, but also carbohydrates and lipids. That can be explained as an attempt by the cyanobacteria to improve the efficiency of photosynthesis in less than optimal light conditions. The highest protein content was obtained under green and white LED illumination (Markou, 2014).

\section{Effect of the Light Intensity on Biomass Growth under Mixotrophic Conditions}

It is already known that Arthrospira can grow in three modes: autotrophic - based on photosynthesis, heterotrophicdepending on organic carbon sources (Vonshak et al., 2000; Chojnacka and Noworyta, 2004; Andrade and Costa, 2007), and mixotrophic, which use those two modes simultaneously (Marquez et al., 1993). Mixotrophic cultivation of A. platensis results in higher overall biomass production in any light intensity used compared to autotrophic and heterotrophic cultures (4 klux for (Chen, 1996); below $150 \mu \mathrm{mol} \mathrm{m}{ }^{-2} \mathrm{~s}^{-1}$ for (Vonshak et al., 2000)). Indeed, the maximal biomass yield was 2.3 times greater in mixotrophic conditions under $150 \mu \mathrm{mol} \mathrm{m} \mathrm{m}^{-2} \mathrm{~s}^{-1}$ light intensity (Rym et al., 2010). The results showed that the amount of biomass obtained under mixotrophic conditions was a result of the combined response of cyanobacterium to light and organic carbon source-glucose. Moreover, the addition of glucose to the cultivation medium in mixotrophic conditions under a light intensity of $150 \mu \mathrm{mol} \mathrm{m} \mathrm{m}^{-2} \mathrm{~s}^{-1}$ resulted in higher EPS yield compared to autotrophic and heterotrophic conditions (Trabelsi et al., 2013). Mixotrophic cultures also have lower light requirements, higher oversaturation levels and can recover quicker from light stresses than autotrophic cultures (Vonshak et al., 2000). Under lower illumination, glucose has a low influence on the maximal biomass concentration and growth rate (Rym et al., 2010).

\section{Effect of UV Radiation on Morphology}

Ultraviolet light is a naturally present environmental factor influencing the outdoor growth of Arthrospira. Cyanobacteria developed various defense mechanisms to protect themselves. First, the cells may avoid the stress-inducing or damaging factor by changing the buoyancy of the trichome or its rotation (Miklaszewska et al., 2012). Secondly, cells may repair the damaged DNA or synthesize DNA de novo (Sinha and Häder, 2002). Another defense mechanism is the production of UV-absorbing compounds like mycosporine-like amino acids (MMAs), scytonemin (Rastogi and Incharoensakdi, 2014) and carotenoids in higher quantity (Rakhimberdieva et al., 2004; Gao and Ma, 2008).

Regardless of its impact at the molecular level, UV is causing morphological changes in the cells that are visible after $2 \mathrm{~h}$ of exposure. The exposure to full solar radiation (UV-B, UV-A, and PAR) has the most destructive effect and leads to severe filaments breakage. In contrast, longer exposure of filaments to only PAR only leads to slight breakage (Wu et al., 2005). In addition, Sarma et al. (2010) showed that, to some extent, PAR light protects filaments from breakage caused by UV radiation when applied simultaneously. It is important to emphasize that the destructive effect of UV is more pronounced at $15-23^{\circ} \mathrm{C}$-temperatures below Arthrospira growth optimum. In temperatures around its optimum, the damages caused by UV exposure are smaller and become visible only after a longer exposure-up to $8 \mathrm{~h}$ (Gao et al., 2008). UV light exposure results in the formation of a tighter helical structure of trichome (Wu et al., 2005; Helbling et al., 2006) and it has already been suggested that this change in morphology is increasing the tolerance to high-light conditions (Jeeji Bai and Seshadri, 1980). Cultivation in the laboratory without UV radiation seems to promote the development of straight filaments (Lewin, 1980; Jeeji Bai, 1985).

\section{Growth in Different Salinities}

Arthrospira is known as an alkalophilic and halophilic organism. Arthrospira species have been reported to grow in the natural environment in a salinity range from 1.1 to $300 \mathrm{~g} / \mathrm{L}$, understood as a total amount of all salts present in the environment (Dadheech et al., 2010). In laboratory conditions, according to literature data, Arthrospira is grown in media with salinity levels varying from 8.5 to $200 \mathrm{~g} / \mathrm{L}$ (Arruda et al., 2009; Pelizer and Moraes, 2009). Many studies focused on establishing the optimal salinity to obtain the highest Arthrospira biomass yields and different media with and without supplementation were utilized. Among the most commonly used media are the ones 
by Zarrouk, Schlösser, Provasoli, Paoletti, and Spirulina Medium (Zarrouk, 1966; Sánchez-Luna et al., 2004; Converti et al., 2006; Tambiev et al., 2011; Ogato et al., 2014). The composition of those media only slightly varies and all of them contain a substantial amount of salts. It is difficult to define which medium is the best since results are contradictory and seem to differ not only between media but also between strains. The biomass yield obtained is most likely dependent upon multiple factors like light intensity, nitrogen, and micronutrients availability, stirring, and pH (Converti et al., 2006; Ravelonandro et al., 2011; Moraes et al., 2013).

Cultivation of Arthrospira in synthetic media is expensive and not economical. Therefore, numerous studies were designed to find the best natural alternative medium without compromising biomass productivity (Materassi et al., 1984; Tredici et al., 1986; Costa et al., 2003; Ogato et al., 2014). A first choice alternative medium would be lake or seawater with proper chemical composition. An example of such studies is the cultivation of Arthrospira in waters from two saline-alkaline lakes located in the Ethiopian rift: Chitu, in which a natural population of A.fusiformis is present and the nearby Shalla, which was devoid of Arthrospira. After supplementing the water from these lakes with a synthetic medium, the yield was comparable to that obtained from the control grown in standard Spirulina medium (Ogato et al., 2014).

\section{Nitrogen Source}

Strains of the genus Arthrospira are usually cultivated in media containing $\mathrm{KNO}_{3}$ or $\mathrm{NaNO}_{3}$ as a primary nitrogen source. However, reports concerning Arthrospira growth in media with different and cheaper nitrogen source are fairly abundant. An extensively studied nitrogen source is urea (Feng and Wu, 2006; Sánchez-Luna et al., 2007; Avila-Leon et al., 2012) as it is quite cheap. However, at higher concentrations, it tends to become toxic because it damages the Photosystem II (Dai et al., 2014) and under alkaline conditions, urea hydrolyses to ammonia, which results in a loss by off-gassing (Danesi et al., 2002). Loss of ammonia to the atmosphere is also a problematic issue if ammonium salts are used. Markou et al. (2014) showed that the ammonium chloride loss as gaseous ammonia ranged from about 17 up to $80 \%$, depending on the initial salt concentration. In another study, Bezerra et al. (2008) also used ammonium chloride as a nitrogen source, but have not reported loss by offgassing under non-light limited conditions during the fed-batch experiment. Cultivation of Arthrospira in waters from the Gulf of Mexico supplemented with anaerobic effluents after pig waste digestion under two light intensities (66 and $144 \mu \mathrm{mol} \mathrm{m} \mathrm{m}^{-2}$ $\mathrm{s}^{-1}$ ) resulted in significant increases in lipids and polysaccharides (Olguín et al., 2001) as compared to the biomass grown in control conditions. Another study investigated the growth of Arthrospira in nitrogen-depleted medium and the effect of such cultivation on cells (Deschoenmaeker et al., 2014). The strain PCC8005 was able to survive long-term cultivation without any external nitrogen source and recovered upon transfer to standard medium. Nevertheless, the lack of nitrogen source resulted in a decrease of protein and phycobilisome contents, downregulation of the inorganic carbon fixation pathway and glycogenolysis as well as upregulation of glutamine synthesis, nitrogen metabolism, carbohydrate synthesis, and both HglK and HglR proteins, which are involved in heterocyst formation in other cyanobacteria.

\section{Indoor and Outdoor Cultivation Methods}

Mass cultivation of photosynthetic organisms such as Arthrospira has been widely studied in order to establish the most economical process to obtain biomass. For indoor cultivation, closed photobioreactors are the most popular choice. They allow the control of cultivation conditions such as $\mathrm{pH}$, light intensity, or $\mathrm{CO}_{2}$ supplementation as well as contamination prevention (Travieso et al., 2001). However, cultivation at the industrial scale is most often performed in large outdoor open-ponds (Borowitzka, 1999). Due to the fact that Arthrospira requires high temperatures in order to grow efficiently, it is often cultivated in regions with high average air temperature and high amounts of sunlight (tropical and sub-tropical regions), which lowers the production costs significantly. However, though economically more sustainable, open-pond cultivations also face certain problems. Those issues, like contaminations, mixing of the cultures, $\mathrm{CO} 2$ utilization efficiency and weather influence have been discussed in a review about engineering solutions for open microalgae mass cultivation (Apel and WeusterBotz, 2015). Engineerig solutions for the above-mentioned problems were presented and a model-based bioprocess and bioreactors development was proposed as a promising tool for further improvement in productivity of microalgae during mass cultivation.

Industrial production of "Spirulina" has existed for many years in countries such as Australia, India, Israel, Japan, Malaysia, China, Chad, and Myanmar, without production data being reported to FAO. The first pilot plant started production in 1973 in Mexico and produced 150 tons of dry "Spirulina" biomass per year. The production increased later to 300 tons per year (Habib et al., 2008). In 1988, yearly worldwide production was estimated on 900 tons of dry biomass (Vonshak and Richmond, 1988; Pulz and Gross, 2004). Between 2000 and 2004 the world production raised to 3,000 tons per year (Pulz and Gross, 2004; Shimamatsu, 2004). In 2010 efficiency of dry mass production reached 90000 tons and remained at this level until last reports from FAO (2016). The largest farm is estimated to produce 500 tons of dry biomass per year (FAO, 2016).

\section{ARTHROSPIRA, HUMAN HEALTH, AND MEDICINE-THE MULTIPLOT STORY}

Because of its chemical compound richness, the members of the Arthrospira genus are potent candidates as sources for bioactive substances. In 1993, the World Health Organization ${ }^{1}$ announced that Arthrospira (formerly named Spirulina) is an "interesting food for multiple reasons, rich in iron and protein, and is able to be administered to children without any risk" (WHO; Credentials|Abundance, 2017). Since then, Arthrospira products are treated as a superfood-a nutrientrich food considered to be especially beneficial for health and

${ }^{1}$ World Health Organization (1993), Geneva, Switzerland. 
well-being' (definition of superfood by Oxford Dictionary ${ }^{2}$ ). The American Food and Drug Administration classified Arthrospira preparations as GRAS (Generally Recognized As Safe) in 2002 (FDA). In 2011, a commission of United States Pharmacopeia reviewed information from human clinical trials, animal studies, and regulatory and pharmacopeial sources and analyzed 31 adverse event reports regarding "Spirulina" to assess potential health concerns. As a result of the performed investigation, the commission assigned a Class A safety rating for S. maxima and $S$. platensis, thereby permitting the admission of quality monographs for these dietary supplement ingredients in USPNF (United States Pharmacopeia and the National Formulary) (Marles et al., 2011).

The pharmacological potential of pure Arthrospira biomass, hot water extracts, purified polysaccharides, phycocyanin, and calcium spirulan preparations has been examined in many studies. Results reveal the ability of these preparations to beat viral infections, act as immunomodulatory factor, antitumor agent, genetic cell damage and cardiovascular diseases protector. Arthrospira powder sold as "Spirulina" in general has no detectable adverse effects on human body, reproductive performance, embryo/fetus development, and growth. Nevertheless, in cultures without GMP (Good Manufacturing Practice) application, Arthrospira biomass may contain low levels of mercury and other heavy metals that constitute a direct health danger (Kim and Lee, 2013; Vicat et al., 2014). Nonetheless, Arthrospira may become an important source of food and feed in the future, as $4 \mathrm{~m}^{2}$ basin produces around $40 \mathrm{~g}$ of dry biomass daily with 10 times lesser requirements of water in comparison to equivalent weight of soybean (Habib et al., 2008).

In the presented review, we aim at demonstrating the broad medical potential of Arthrospira biomass, extracts, and products, summarized in Table 2. Due to the diversity of material used in research-from pure laboratory strains to commercial products sold as "Spirulina," these authors decided to reproduce the nomenclature of the cited original papers.

\section{Substances That Play a Pivotal Role in Arthrospira Multi-directional Activity}

The first analysis performed by Leonard and Compere (1967) showed that $45 \%$ of the dry biomass of Arthrospira was composed of proteins. Recent research revealed that the protein content may in fact be higher, up to $77 \%$ of the dry weight, depending on external conditions. Indeed, the analyzed protein content in all strains cultivated in the laboratory was higher than for the biomass collected from open ponds (Ciferri, 1983). The pigments content appear to depend on the temperature and light intensity (Kumar et al., 2011) and the amino acids content depends from the salinity (Volkmann et al., 2008; Wang et al., 2013).

The nutritional value of Arthrospira was reviewed by Miklaszewska et al. (2008a). Here we present the most important dietary aspects. Arthrospira is a valuable source of protein, not only because its high concentration in the dry biomass but also

${ }^{2}$ Oxford Dictionary (2017). Available online at: https://en.oxforddictionaries.com/ definition/superfood (Accessed February 16, 2017). thanks to the amino acids composition and high digestibility. It is worth mentioning that Arthrospira biomass contains all 8 exogenic and 12 endogenic amino acids. The most abundant amino acids are leucine (10.9\%), valine (7.5\%), and isoleucine $(6.8 \%)$. Although the content of cysteine and methionine is the lowest of all present amino acids, it is still higher compared to cereals or vegetables.

The lipid content of Arthrospira biomass is difficult to determine due to the differences in efficiency of extraction methods and changes in its actual content. Reported data vary from 1.5 to $12 \%$ of dry mass (Ciferri, 1983). Notably, the gamma linolenic acid (GLA) synthesized by the delta- 6 fatty acid desaturase can reach up to $40 \%$ of all fatty acids in Arthrospira platensis (Murata et al., 1996). It acts as a precursor of prostaglandins, tromboxanes, and leukotrienes. That makes Arthrospira one of the best-known sources of $\gamma$-linolenic acid. Additionally, Arthrospira extracts contain vitamin $\mathrm{F}$, linolenic, and arachidonic acids, fatty acids that promote cholesterol normalization (Miklaszewska et al., 2008a). However, the presence of arachidonic acid may be the effect of improper sample treatment during the analytical procedure as cyanobacteria do not possess fatty acid elongases required for C20 fatty acids production (Iliev et al., 2011).

Arthrospira carbohydrates content vary from 10 to $15 \%$ of dry biomass, mainly as rhamnose and glycogen. An important carbohydrate, mesoinositol phosphate, reaches a concentration of $350-850 \mathrm{mg} / \mathrm{kg}$ dry biomass. This compound is a perfect source of organic inositol (Falquet and Hurni, 1997). High molecular polysaccharides extracted from the Arthrospira biomass or culture medium have anticancer, immunostimulatory effects and can constitute scaffolds for tissue/organ regeneration in regenerative medicine (de Morais et al., 2010, 2014; Nielsen et al., 2010; Kurd and Samavati, 2015).

Although proteins, carbohydrates, and lipids are the building material of the cell, other trace elements significantly impact human metabolism. Arthrospira contains many essential minerals and trace elements like potassium, zinc, calcium, magnesium, selenium, manganese, iron, phosphorus, that are absorbed from its culture medium and transformed into chelated, easily absorbed forms. Potassium is an essential enzyme activator in muscle and heart, responsible also for maintaining the electrolyte balance. Iron consumed with Arthrospira is two times better assimilated than the one eaten with vegetables or meat (Puyfoulhoux et al., 2001).

Arthrospira cells contain carotenoids in different forms: $\alpha$ carotene, $\beta$-carotene, cryptoxanthin, zeaxanthin, xanthophylls, echinenone, lutein. Eighty percent of all carotenoids present in Arthrospira are made by $\beta$-carotene $(700-1,700 \mathrm{mg} / \mathrm{kg}$ of biomass) and cryptoxanthin $(100 \mathrm{mg} / \mathrm{kg})$, which are both precursors of vitamin A. Arthrospira supplements are efficient in eliminating vitamin A deficiency (Falquet and Hurni, 1997; Miklaszewska et al., 2008a; Naturalways, 2017).

Arthrospira biomass contains also other enzymatic pigments such as chlorophyll, phycocyanin, porphyrin. Chlorophyll supports intestine peristalsis, normalizes secretion of digestive acids, decreases secretion of pepsin and soothes inflammation. Porphyrin forms a nucleus of hemoglobin, what makes it an 


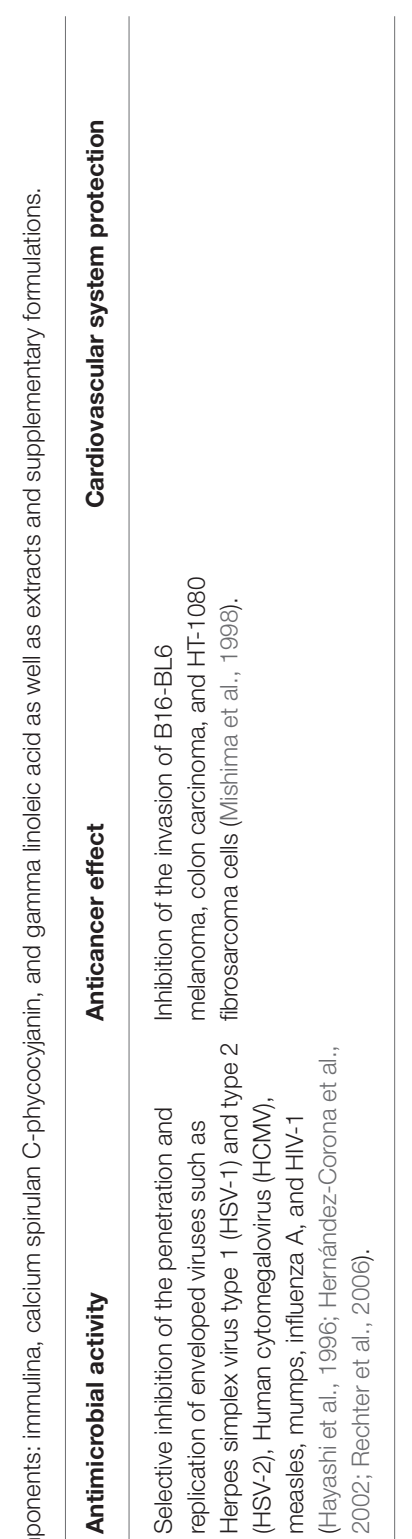

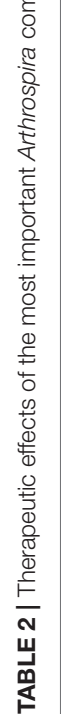

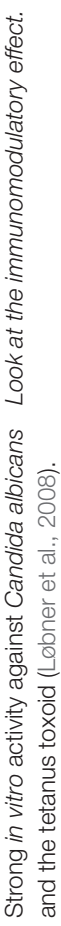

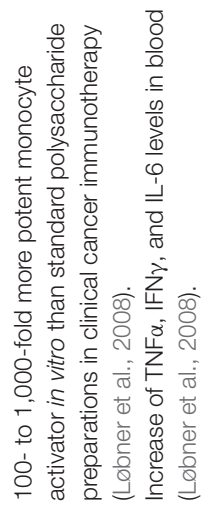

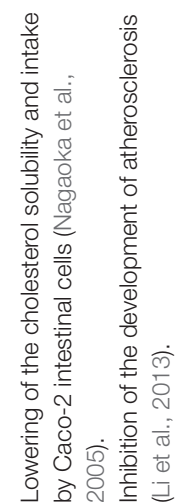

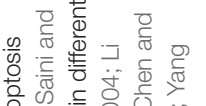

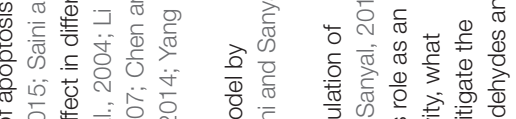

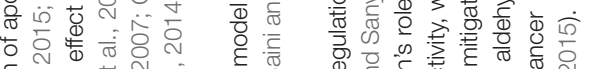

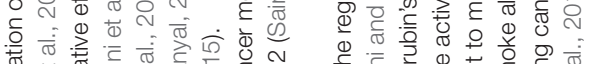

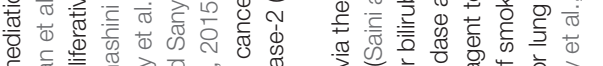

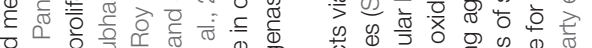

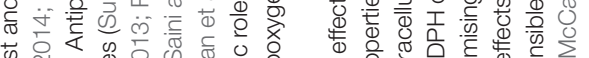

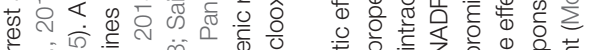

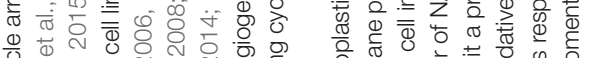

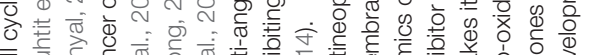

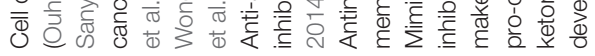

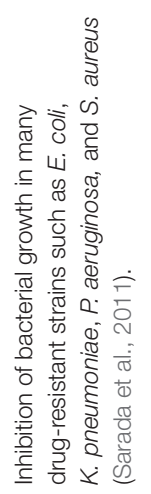

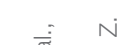
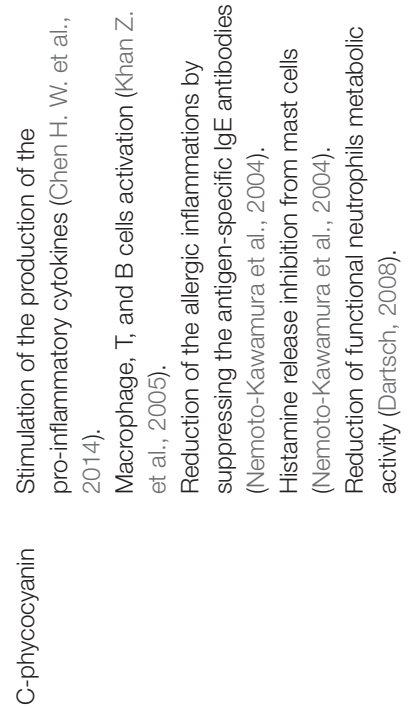

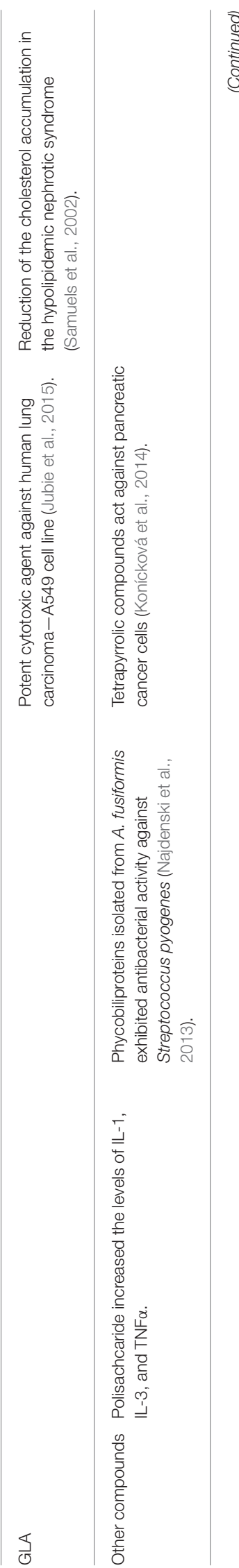




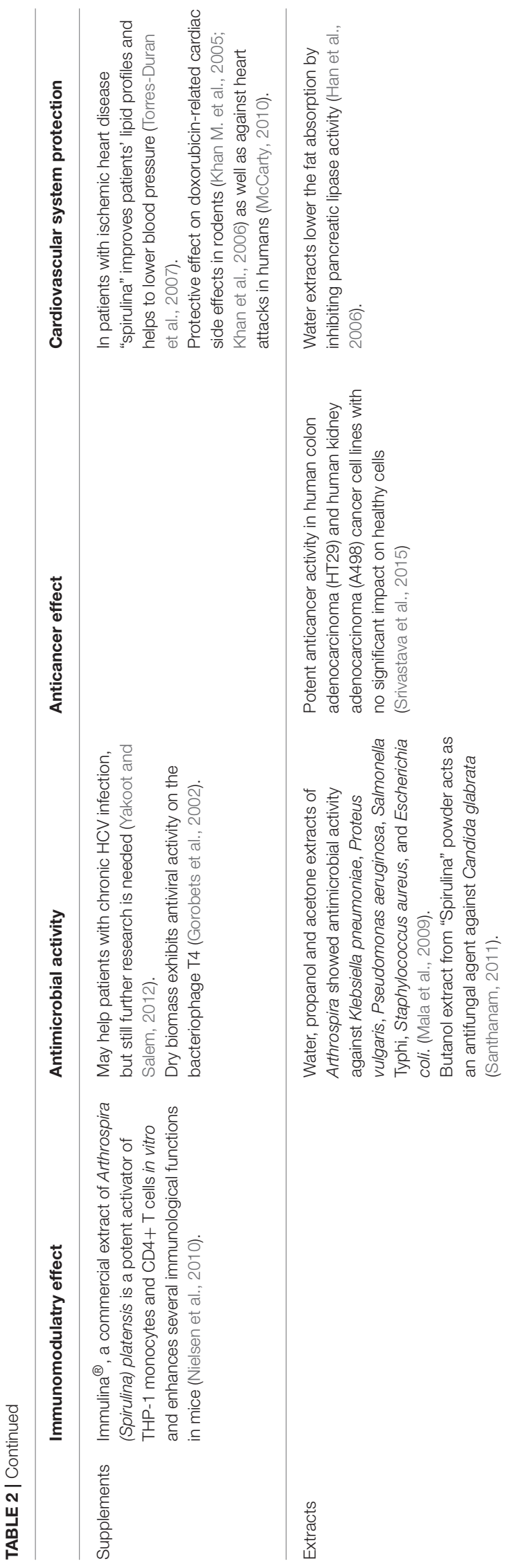

important factor in the maintenance of healthy red blood cells. Phycocyanin is related to bilirubin, essential for liver functions and digestion of amino acids. Apart from standard functions carotenoids and phycocyanin are antioxidants, reduce free radicals and have potential anti-tumor properties (Pervushkin et al., 2001; Miklaszewska et al., 2008a).

Besides its nutritional values, the consumption of Arthrospira as a food supplement gives other advantages. The cell wall of Arthrospira does not contain cellulose, which make it very easy to digest. Additionally, Arthrospira biomass has a very low level of nucleic acids and due to alkaline growth conditions, it is not easily contaminated by most of the human pathogens (Ciferri, 1983). However, in a recent report of the Vardaka research group, 31 dietary supplements sold as "Spirulina" on the Greek market contained 469 different bacterial OTUs. Among them were toxic cyanobacteria from the Microcystis, Nostoc, and Anabaenopsis genera. Moreover, supplements were contaminated with human pathogens (Vardaka et al., 2016). This highlights the need to control the quality of the production, as for any other foodstuff.

Detailed research has been conducted to confirm the therapeutic effects of some compounds that are unique for Arthrospira, including (I) calcium spirulan (II) immulina (III) C-phycocyanin and (IV) $\gamma$-linolenic acid (GLA).

Calcium spirulan (Ca-SP) is a complex polysaccharide composed of rhamnose, ribose, mannose, fructose, galactose, xylose, glucose, glucuronic acid, galacturonic acid, sulfate, and calcium (Lee et al., 1998, 2000). It was shown to inhibit the replication of enveloped viruses from different genera (Hayashi et al., 1996). Immulina is also a high-molecularweight polysaccharide and exhibits significant effects as an immunostimulator (Nielsen et al., 2010). C-Phycocyanin is an unusual nontoxic fluorescent protein having an antioxidative, anti-inflammatory and antitumor potential (de Jesus Raposo et al., 2013). Studies suggest it is more potent in colon cancer prevention than vitamin $\mathrm{E}$ and germanium-132 (Chen and Zhang, 1995). The $\gamma$-linolenic acid controls cholesterol levels and protects the cardiovascular system (Białek and Rutkowska, 2015).

\section{Arthrospira Empowers Natural Immunological Responses}

Arthrospira components are potent immunostimulating agents, they enhance the resistance to infections, have the capacity to influence hematopoiesis and stimulate the production of antibodies, especially IgA (Nemoto-Kawamura et al., 2004) and cytokines. Compounds from cyanobacteria are known to empower the immune system to inhibit carcinogenesis and assist natural healing mechanisms. Indeed, Arthrospira appears much more effective in Th1-response stimulation than Th2 (Mao et al., 2000).

Immulina is $100-1000 x$ more active as monocyte activation factor in vitro than polysaccharide preparations that were being used at the time in clinical settings for cancer immunotherapy (Løbner et al., 2008). Immulina raises TNF $\alpha$, IFN $\gamma$, and IL-6 blood levels (Løbner et al., 2008). Polysaccharide extracts from "Spirulina" significantly increased the levels of IL-1, IL-3, and TNF $\alpha$. 
The C-phycocyanin also exhibits potent immunostimulatory effects by stimulating the generation of pro-inflammatory cytokines, which in turn boost the cytotoxic functions of CTL (cytolytic T lymphocytes) and NK (natural killer) cells activity (Chen H. W. et al., 2014). Moreover, pro-inflammatory cytikines activate macrophages, T, and B cells (Khan Z. et al., 2005). Studies suggest that this multi-directional effect of Arthrospira consumption is due to an involvement in signaling responses through toll-like receptors in blood cells (Balachandran et al., 2006; Kawanishi et al., 2013).

Arthrospira extracts not only increase resistance to infectious diseases or natural healing mechanisms but also can modulate allergic responses. They sustain the functions of mucosal immunological mechanisms and reduce allergic inflammations by suppressing the antigen-specific IgE antibodies (NemotoKawamura et al., 2004). So far, Mao et al. (2005) observed positive results with "Spirulina" dietary supplementation (product delivered by Earthrise Nutritionals, Inc., Irvine, CA) to protect against allergic rhinitis. Another anti-inflammatory effect of "Spirulina" phycocyanin is the histamine release inhibition from mast cells (Nemoto-Kawamura et al., 2004) and the reduction of functional neutrophils metabolic activity (four "Spirulina" preparations, Dartsch, 2008).

\section{Antiviral Activity}

Although its exact mode of action is unknown, scientists suspect that unique nutrients play an important role in $A$. platensis function as an antiviral (Blinkova et al., 2001). The calcium spirulan, isolated from hot water extracts is very effective against a variety of viruses and it inhibits the replication of enveloped viruses such as Herpes simplex virus type 1 (HSV-1) and type 2 (HSV-2), Human cytomegalovirus (HCMV), measles, mumps, influenza A, and HIV-1 in in vitro conditions (HernándezCorona et al., 2002; Rechter et al., 2006). Study performed by Hayashi et al. (1996) indicated that calcium spirulan selectively inhibits the penetration of the virus particle into the host cell and is more effective than dextran sulfate. The most probable mode of action is the conformational chelation of sulfate groups on the surface of the virus envelope.

Encouraging results were observed when Arthrospira supplements were administered to patients with chronic HCV infection (Yakoot and Salem, 2012). Nevertheless, further research is needed to confirm this effect.

Interestingly, dried $A$. platensis exhibits antiviral activity on the bacteriophage T4 (Gorobets et al., 2002).

\section{Antibacterial and Antifungal Properties}

Compounds isolated from Arthrospira cells can also act as antimicrobial agents. Animal studies suggest that they enhance natural immunological clearance mechanisms after bacterial infections with Escherichia coli or Staphylococcus aureus (Quereshi et al., 1995).

Mala et al. (2009) studied the antimicrobial activity of various organic and aqueous extracts of A. platensis. In agar-solid diffusion tests, a water extract of Arthrospira (WEA) showed a maximal antimicrobial activity ( $18.00 \mathrm{~mm}$ inhibition zone) in case of Klebsiella pneumoniae and a minimum activity against
Proteus vulgaris $(10.0 \mathrm{~mm})$. A propanol extract (PEA) exhibited at least a $7.0 \mathrm{~mm}$ inhibition zone for Pseudomonas aeruginosa and $8.0 \mathrm{~mm}$ for E. coli. The acetone extract (AEA) displayed the highest biological activity with $17 \mathrm{~mm}$ inhibition zone against $K$. pneumonia, moderate activity in case of Salmonella Typhi and a $10.0 \mathrm{~mm}$ inhibition zone with $P$. aeruginosa, E. coli, and $S$. aureus. Sequential extracts of $A$. platensis exhibited the maximal antimicrobial activity and an inhibition zone of $25.3 \mathrm{~mm}$ was observed for $K$. pneumoniae and $16.0 \mathrm{~mm}$ for $P$. vulgaris. The authors assigned the antimicrobial activity to the peptides detected in the FTIR spectrum of this extract.

Microalgal cultures of $A$. platensis displayed significant antimicrobial activity against six Vibrio strains (Pradhan et al., 2011). Phycobiliproteins isolated from A. fusiformis exhibited antibacterial activity against Streptococcus pyogenes (Najdenski et al., 2013). The C-phycocyanin purified from A. platensis was able to inhibit the bacterial growth in many drug-resistant strains such as E. coli, K. pneumoniae, $P$. aeruginosa, and S. aureus (Sarada et al., 2011). Besides antimicrobial and antiviral properties, Arthrospira formulations show antifungal characteristics. Butanol extract from "Spirulina" powder was tested as a potential antifungal agent against Candida glabrata and caused a $13 \mathrm{~mm}$ growth inhibition zone in test plates (Santhanam, 2011). The previously mentioned immulina was found to be strongly active in vitro against Candida albicans and the tetanus toxoid (Løbner et al., 2008).

Recently, Duda-Chodak (2013) demonstrated that the water extract of Arthrospira has a notable impact on microorganisms. An inhibitory activity was shown against Bacillus subtilis, Micrococcus luteus, Rhodotorula, and Penicillum. Water extract of Arthrospira also strongly stimulated Alicyclobacillus acidoterrestris, and Geotrichum growth. Higher concentrations promoted the development of mycelium and production of conidiophores by Cladosporium and Aspergillus niger.

A. platensis was documented to be used as a bioreactor for production of silver nanoparticles. The latter are powerful toxic agents against the cancer promoter cyanobacterium, Microcystis aeruginosa (El-Sheekh and El-Kassas, 2014).

\section{Activity against Tumors}

Strong immunological influence and antioxidant activity predestinates Arthrospira to become a useful support for antitumor immunotherapy, both as a preventive and therapeutical agent. Konícková et al. (2014) demonstrated an antioxidative activity of $A$. platensis and its tetrapyrrolic compounds against pancreatic cancer cells. Kurd and Samavati (2015) showed that polysaccharides extracted from A. platensis had strong scavenging activities in vitro on DPPH (stable nitrogen-centered free radical) and hydroxyl radicals (but in this case lower than vitamin C). Studies indicate that Arthrospira or its components also have radioprotectant and cytotoxic properties. MB-6 is a novel herbal preparation containing fermented soybean extract, green tea extract, Antrodia camphorata mycelia, spirulina, grape seed extract, and curcumin extract. This supplement was proven to be a promising support that increases the effectiveness of chemotherapy in patients with metastatic colorectal cancer (Chen W. T. et al., 
2014). Radioprotectant and cytotoxic effect of Arthrospira was observed in combined therapy with metronidazole in relapsed vulvar cancer (VVC) (Kiziltan et al., 2015).

Srivastava et al. (2015) screened five cyanobacterial strains, including Arthrospira sp. CCC729 for anticancer potential. Tests were performed on human colon adenocarcinoma (HT29) and human kidney adenocarcinoma (A498) cancer cell lines. Crude extracts and TLC eluates of Arthrospira sp. CCC729 exhibited potent anticancer activity. Apoptotic studies in cancer cell line (A498) and normal human epithelial cells (MCF-10A) revealed no significant impact on MCF-10A cells, in contrast to cancer cells.

During investigation performed on $\mathrm{DMH}$-induced rat colon cancerogenesis, the C-phycocyanin promoted the arrest of the cell cycle by downregulating cyclin D1, cyclin E, CDK2, and CDK4 (Saini and Sanyal, 2015). Moreover, this pigment mediated apoptosis through the p53 activation pathway. C-phycocyanin also promoted antiproliferation by restraining PCNA expression and reduced cell survival via inhibiting NFkB (p65). Cphycocyanin demonstrated an anti-angiogenic role in cancer model by inhibiting cyclooxygenase-2 (Saini and Sanyal, 2014). Furthermore, it exerts antineoplastic effects via the regulation of membrane properties, raising calpain- 9 and PPAR $\gamma$ expression while suppressing Wnt/ $\beta$-catenin signaling (Saini and Sanyal, 2014).

C-phycocyanin was also reported to be efficient against mouth tumor in long-term smokers. In rodents treated with a combination of Arthrospira and Dunaliella extracts, the supplementation prevented the mouth-tumor development (Schwartz et al., 1988). Mathew et al. (1995) have evaluated the chemopreventive activity of A. fusiformis in reversing oral leukoplakia in pan-tobacco chewers in Kerala, India. Complete regression of lesions was observed in $45 \%$ evaluable subjects supplemented with "Spirulina," as opposed to $7 \%$ in the placebo arm (Mathew et al., 1995). The aldehydes and ketones from tobacco smoke activate NADPH oxidase complexes in vascular tissues and in the lungs. Phycocyanin mimics cell intracellular bilirubin's role as an inhibitor of NADPH oxidase activity (McCarty et al., 2015), what makes it a promising agent to mitigate the pro-oxidative effects of smoke aldehydes and ketones. In turn, methyl gamma linoleate from A. platensis appeared to be a potent cytotoxic agent against human lung carcinoma-A549 cell line (Jubie et al., 2015).

Phycocyanin significantly decreases HeLa cells multiplication in comparison to control cells (Li et al., 2006, 2013; Yang et al., 2014). Furthermore, it activates the apoptotic pathway, including cell shrinkage in HeLa cell lines. Beaten cancer cells are enfeebled and incapable of rejuvenation. Ouhtit et al. (2014) confirmed that an A. platensis treatment of DMBA-induced rat mammary tumor decreased the cancer incidence from 87 to $13 \%$. Immunohistochemical analysis revealed that supplementation with "Spirulina" reduced the expression of Ki-67 and estrogen $\alpha$. In vitro studies showed that a "Spirulina" treatment inhibited cell proliferation, increased $\mathrm{p} 53$ expression, followed by the increased expression of its downstream target gene, Cdkn1a [alias p21 or p21(Waf1/Cip1)]. A. platensis increases Bax and decreases Bcl-2 expression, indicating the induction of apoptosis also $48 \mathrm{~h}$ after treatment.

Pan et al. (2015) showed the inhibitory effect of phycocyanin on the proliferation of the ovarian cancer SKOV-3 cell line. Phycocyanin also induced the apoptosis by the mitochondrial pathway.

The oral treatment with $A$. maxima performed by ChamorroCevallos et al. (2014) significantly reduced the detrimental effect of benzo[ $\alpha]$ pyrene on the quality of mouse semen, protected from $\mathrm{B}[\alpha] \mathrm{P}$-induced pre- and post-implant losses in the male dominant lethal test, and from $\mathrm{B}[\alpha] \mathrm{P}$-induced postimplantation losses in treated females. Those results demonstrate the protective effects of $A$. maxima against $\mathrm{B}[\alpha] \mathrm{P}$-induced mutagenicity in germ cells.

Antioxidant and anti-inflammatory effects of $A$. platensis have been shown in UVB-induced skin carcinogenesis in animal models. Investigators used wild-type and Ogg1 knockout(KO) mice, as the absence of the enzyme produced by this gene raises the tumor incidence in response to UVB exposure. Dietary supplementation with $A$. platensis suppressed cancer development in both genotypes (Yogianti et al., 2014). Calcium spirulan from Arthrospira exhibited valuable antitumor characteristics, it inhibited the invasion of B16-BL6 melanoma, Colon 26 M3.1 carcinoma, and HT-1080 fibrosarcoma cells through reconstituted basement membrane (Mishima et al., 1998).

In vitro studies indicated that phycocyanin is able to diminish proliferation of leukemia cell line K-562 about 49\% (Subhashini et al., 2004) and even 50\% in case of hepatocellular carcinoma (liver cancer cell lines) S- and R-HepG2 cells (Roy et al., 2007).

Sometimes, better results are obtained when the compounds are used in combination. The mixing of phycocyanin with selenium demonstrates antiproliferative activity against melanoma A375 cells and human breast adenocarcinoma MCF-7 cells (Chen and Wong, 2008). A combination of selenium and "Spirulina" was also patented as the anticancer delivery vehicle (Riva and Oreal, 2013).

\section{Cardiovascular System Protection}

Arthrospira extracts and compounds may play an important role in the prevention of cardiovascular diseases. They lower the blood pressure, plasma lipid concentration, especially triacylglycerols. They indirectly modify total cholesterol and HDL/LDL (high- to low-density lipoprotein rates). Animal studies indicate that Arthrospira could be a novel preventive tonic for the heart and whole cardiovascular system. Nevertheless, human trials are still too small to prove this effect. All animal studies, preclinical and clinical trials are clearly reviewed by Deng and Chow (2010) in Cardiovascular Therapeutics.

"Spirulina" may be a prominent dietary supplement for patients with ischemic heart disease as it improves patients' lipid profiles and helps to lower blood pressure (Torres-Duran et al., 2007). In rodents, Arthrospira can have a protective effect on doxorubicin-related cardiac side effects (Khan M. et al., 2005; Khan et al., 2006) as well as be protective against heart attacks in humans (McCarty, 2010). Water extracts lower the fat absorption by inhibiting pancreatic lipase activity (Han et al., 2006). 
Phycocyanin from "Spirulina" has a high bile binding capacity, lowers cholesterol solubility and intake by Caco-2 intestinal cells (in comparison to casein) (Nagaoka et al., 2005). In mice, C-phycocyanin can promote the CD59 gene expression. This activity prevents smooth muscle cell proliferation and the apoptosis of endothelial cells, reducing blood fat levels. In consequence, C-phycocyanin inhibits the development of atherosclerosis (Li et al., 2013). The GLA present in Arthrospira reduces cholesterol accumulation in the hypolipidemic nephrotic syndrome (Samuels et al., 2002).

\section{Biomaterials and Bioactive Substances from Arthrospira in Tissue Engineering}

Polyhydroxyalkanoates (PHAs) are biodegradable and biocompatible polymers for tissue or organ scaffold construction in regenerative medicine. They can be extracted from different microorganisms including Arthrospira (Jau et al., 2005). Replacement of commercially available PHA biopolymers with equivalents obtained from Arthrospira or/and containing its biomass significantly increases the eucaryotic cell proliferation and decreases the risk of transplant rejection (de Morais et al., 2014). Since 2007, de Morais et al. (2010) have been studying the development of nanofibers produced from PLA (polylactic acid), polyethylene oxide and PHB (polyhydroxybutyrate) extracted from Arthrospira LEB 18 strain and incorporation of its compounds in artificial extracellular matrices. Their observations reveal that addition of LEB 18 biomass increases nanofibers conductivity (de Morais et al., 2010). PHB nanofibers from LEB 18 have higher mechanical durability with enhanced elasticity, tensile strength, and breaking elongation. Those characteristics support nutrient, growth factors, and metabolism byproducts distribution (de Morais et al., 2014).

A study carried out to compare poly-D,L-lactic acid (PDLLA) associated with LEB 18 biomass with classic PDDLA in the animal model of skin injury disclosed that PDDLLA/Sp scaffolds were more moldable and had better adherence to the wound (Steffens et al., 2014). The same authors showed that PDDLA/Sp increased cells viability in comparison to simple PDDLA matrices (Steffens et al., 2013). Formerly described antimicrobial, antiinflammatory and immunostimulatory effects of biocompounds from Arthrospira provide additional benefits in biomatrices produced from cyanobacteria. They promote natural wound healing processes and minimize the risk of infection (de Morais et al., 2014).

\section{Other Effects and Perspectives}

Some observed beneficial effects of Arthrospira supplementation cannot be classified, but their existence underlines the multiple therapeutical possibilities and how to take advantage of those unusual cyanobacteria.

Studies worth mentioning show that Arthrospira promotes the growth of probiotic microbiota (Parada et al., 1998; KordowskaWiater et al., 2011) from human gut, thus boosting the production of $\mathrm{B} 6$ vitamin that aids in energy release. This fact and its high content of rhamnose, glycogen, and GLA, which also participate in energy release, could predestine Arthrospira to be a potential medication in chronic fatigue syndrome.
Notwithstanding, Arthrospira activity in four N-of-1 doubleblind, randomized trials is comparable to placebo (Baicus and Baicus, 2007).

Arthrospira can turn out to be useful for aging-related diseases. A study performed on rats suggests it enhances expression level of the beta-adrenergic receptor in brain tissue, which decreases with age and is connected with dementia in elderly people (Gemma et al., 2002). Another animal study demonstrates "Spirulina"'s ability to protect neurons in the $\alpha$ synuclein model of Parkinson Disease (Pabon et al., 2012). In rodents, it also exhibits protective effects against drug-related serious renal failure (Kuhad et al., 2006a,b; Lim et al., 2012). "Spirulina" also may have a particular utility in mitigating adverse effects of alcohol consumption thanks to its inhibitory effect on NADPH oxidase and certain nutraceuticals, including taurine, pantethine, and lipoic acid that may have a potential to boost conversion of acetaldehyde to acetate (McCarty, 2013). Due to the good ability to accumulate metal ions from solutions, Arthrospira can be a prominent source of therapeutical nanoparticles. The assimilation process is $\mathrm{pH}$-independent and may be a part of the biofunctionalized (antibacterial) $\mathrm{Au}$ nanoparticles biosynthesis in Arthrospira platensis (Savvaidis, 1998; Suganya et al., 2015).

\section{Arthrospira Formulations as Cosmetics}

The abundance of natural bioactive compounds makes Arthrospira extracts perfect for use in commercial as well homemade cosmetics. Formulas containing "Spirulina" are mostly sold as anti-aging products that combat the action of free radicals, provide hydration, and protection to the skin (e.g., Patent EP2695604 A1 ${ }^{3}$ ). Due to its antimicrobial activity, cosmetics against acne, and other bacterial skin infections are enriched with "Spirulina" extracts (W\&P Cosmetics) ${ }^{4}$.

\section{Cyanobacteria from the Arthrospira Genus in Animal Diet Supplementation}

Previously, animals were fed with Arthrospira to examine the effect on a living organism, which was a preliminary model for human nutrition (Fevrier and Seve, 1975). Nowadays, "Spirulina" is treated as a valuable supplement that supports animal wellbeing and their products quality.

Dietary "Spirulina" supplementation in poultry influences both the yellowness and redness of broiler flesh (Toyomizu et al., 2001b), increases several immunological functions, rising resistance to infections (Qureshi et al., 1996; Al-Batshan et al., 2001) and could be as effective as the diet with synthetic pigment in producing an agreeable egg yolk color (Zahroojian et al., 2011).

Saeid et al. (2013) performed studies focused on the effect of supplementation of $A$. maxima enriched with $\mathrm{Cu}$ on the production performance, metabolism and physiological parameters in fattening pigs. Examination revealed that

${ }^{3}$ Patent EP2695604A1 - Spirulina-Containing Cosmetic Composition and Cosmetic Treatment Method (2017). Google Books. Available online at: http://www. google.com/patents/EP2695604A1?cl=en\#backward-citations (Accessed January 24, 2017).

${ }^{4}$ W\&P Cosmetics (2016). Available online at: http://wp-cosmetics.pl/ (Accessed February 16, 2017). 
supplementation with "Spirulina" extract reduced the liver toxic stress and total cholesterol levels by $10 \%$, rose the glucose level in blood, which may indicate a better energy metabolism and caused a more intense red color of the meat (Saeid et al., 2013).

\section{CONCLUSIONS}

Recent progress in genomics and molecular biology allowed for a better understanding of extraordinary microorganisms - the edible cyanobacteria from the Arthrospira genus. Phylogenetic analyses and bioinformatic approaches shed a new light on genomes' structure and obstacles in genetic engineering. Genetic analyses identified numerous genes responsible for hydrogen production, stress adaptation, restriction-modification systems, and others, unraveling the processes sustaining the functions of the organisms. Genome and proteome studies have proven the absence of toxicity factors, supporting the idea that Arthrospira products are safe to consume. Studies conducted for many years showed that Arthrospira was an organism extremely resistant to environmental stresses. As a rich source of macro- and microelements, vitamins, pigments, protein, polysaccharides, GLA, and other bioactive compounds, it has become a vivid object of interest in food and health industry. Increased interest in this organism results in higher demand for biomass production. Therefore, multiple studies aiming at improving its cultivation conditions and lowering the costs were carried on. Arthrospira was also proven to be very valuable from the medical point of view. Numerous researches conducted on animal models and patients confirmed its immunomodulatory properties, which is strictly connected with antitumor activity against different types of lesions. Apart from empowering human immunological response, chemical compounds extracted from Arthrospira exhibits antibacterial, antifungal, and antiviral activity. Interestingly,

\section{REFERENCES}

Al-Batshan, H. A., Al-Mufarrej, S. I., Al-Homaidan, A. A., and Qureshi, M. A. (2001). Enhancement of chicken macrophage phagocytic function and nitrite production by dietary Spirulina platensis. Immunopharmacol. Immunotoxicol. 23, 281-289. doi: 10.1081/IPH-100103866

Andrade, M. R., and Costa, J. A. (2007). Mixotrophic cultivation of microalga Spirulina platensis using molasses as organic substrate. Aquaculture 264, 130-134. doi: 10.1016/j.aquaculture.2006.11.021

Apel, A. C., and Weuster-Botz, D. (2015). Engineering solutions for open microalgae mass cultivation and realistic indoor simulation of outdoor environments. Bioprocess Biosyst. Eng. 38, 995-1008. doi: 10.1007/s00449-015-1363-1

Arruda, R. D. O. M., Brito, A. W., Silva, R. R. D., and Moraes, I. D. O. (2009). Fermentação de Spirulina platensis sob condições naturais de temperatura $e$ insolação. Revista Saúde-UnG. 3, 16-19.

Avila-Leon, I., Chuei Matsudo, M., Sato, S., and de Carvalho, J. C. (2012). Arthrospira platensis biomass with high protein content cultivated in continuous process using urea as nitrogen source. J. Appl. Microbiol. 112, 1086-1094. doi: 10.1111/j.1365-2672.2012.05303.x

Badri, H., Monsieurs, P., Coninx, I., Wattiez, R., and Leys, N. (2015). Molecular investigation of the radiation resistance of edible cyanobacterium Arthrospira sp. PCC 8005. Microbiologyopen 4, 187-207. doi: 10.1002/mbo 3.229 the probable mechanism of action against enveloped viruses is so universal that "Spirulina" extracts inhibit internalization and replication of potentially every enveloped virus, including HIV-1 and HCV. Fatty acids, especially GLA provide a protective effect for the cardiovascular system, regulating cholesterol levels. A recent development of modern medicine-tissue engineering - can take advantage of Arthrospira polysaccharides used for scaffold construction in tissue/organ regeneration process. The addition of biocompounds from Arthrospira enhances stem cells proliferation and promotes wound healing by supporting the immunological system and providing nourishing substances. Other valuable effects worth mentioning include the promotion of human gut microflora growth, clearance from different types of toxins and neuron anti-aging properties.

\section{AUTHOR CONTRIBUTIONS}

The authors of the general work conception are KW and MW. Reviewers and actual authors of the manuscript text are MAF (genetic section), AM (physiology), MDF (medicine). Critical revision for important intelectual content: AW, KW, and MW. Proofreading, edition, and final approval of the version to be published was made by all authors mentioned above. All questions should be addressed to KW.

\section{FUNDING}

This work was supported by Medical University of Gdańsk and was a result of Scientific and Technical Cooperation projects between Republic of Poland and French-speaking Community and Walloon region of Belgium (Wallonia Brussels International) 2014-2016 and 2017-2019. AW is Research Associate of the FRS-FNRS of Belgium.
Baicus, C., and Baicus, A. (2007). Spirulina did not ameliorate idiopathic chronic fatigue in four N-of-1 randomized controlled trials. Phytother. Res. 21, 570-573. doi: $10.1002 /$ ptr.2114

Balachandran, P., Pugh, N. D., Ma, G., and Pasco, D. S. (2006). Toll-like receptor 2-dependent activation of monocytes by Spirulina polysaccharide and its immune enhancing action in mice. Int. Immunopharmacol. 6, 1808-1814. doi: 10.1016/j.intimp.2006.08.001

Baurain, D., Renquin, L., Grubisic, S., Scheldeman, P., Belay, A., and Wilmotte, A. (2002). Remarkable conservation of internally transcribed spacer sequences of Arthrospira ('Spirulina') (Cyanophyceae, Cyanobacteria) strains from four continents and of recent and 30-year old dried samples from Africa. J Phycol. 38, 384-393. doi: 10.1046/j.1529-8817.2002.01010.x

Bezerra, R. P., Matsudo, M. C., Converti, A., Sato, S., and de Carvalho, J. C. M. (2008). Influence of ammonium chloride feeding time and light intensity on the cultivation of Spirulina (Arthrospira) platensis. Biotech. Bioeng. 100, 297-305. doi: 10.1002/bit.21771

Białek, M., and Rutkowska, J. (2015). The importance of $\gamma$-linolenic acid in the prevention and treatment. Postepy Hig Med Dosw. 69, 892-904. doi: 10.5604/17322693.1162991

Blinkova, L. P., Gorobets, O. B., and Baturo, A. P. (2001). Biological activity of Spirulina. Zh. Mikrobiol. Epidemiol. Immunobiol. 114-118.

Borowitzka, M. A. (1999). Commercial production of microalgae:ponds, tanks, tubes and fermenters. J. Biotechnol. 70, 313-321. doi: 10.1016/S0168-1656(99)00083-8 
Carrieri, D., Ananyev, G., Lenz, O., Bryant, D. A., and Dismukes, G. C. (2011). Contribution of a sodium ion gradient to energy conservation during fermentation in the cyanobacterium Arthrospira (Spirulina) maxima CS-328. App. Environ. Microbiol. 77, 7185-7194. doi: 10.1128/AEM.00612-11

Castenholz, R. W., Wilmotte, A., Herdman, M., Rippka, R., Waterbury, J. B., Iteman, I., et al. (2001). "Phylum, B. X., Cyanobacteria, oxygenic photosynthetic bacteria," in Bergey's Manual of Systematic Bacteriology, 2nd Edn., Vol. 1, eds G. M. Garrity, D. R. Boone, and R. W. Castenholz (New York, NY: Springer-Verlag), 473-597.

Chamorro-Cevallos, G., Garduño-Siciliano, L., Martínez-Galero, E., MojicaVillegas, A., Pages, N., and Gutiérrez-Salmeán, G. (2014). The protective effect of dietary Arthrospira (Spirulina) maxima against mutagenicity induced by benzo[alpha]pyrene in mice. J. Med. Food. 17, 527-534. doi: $10.1089 /$ jmf.2013.0109

Cheevadhanarak, S., Paithoonrangsarid, K., Prommeenate, P., Kaewngam, W., Musigkain, A., Tragoonrung, S., et al. (2012). Draft genome sequence of Arthrospira platensis C1 (PCC9438). Stand Genomic Sci. 6,43-53. doi: $10.4056 /$ sigs. $2525955 y$

Chen, F. (1996). High cell density culture of microalgae in heterotrophic growth. Trends Biotechnol. 14, 421-426. doi: 10.1016/0167-7799(96)10060-3

Chen, F., and Zhang, Q. (1995). Inhibitive effects of spirulina on aberrant crypts in colon induced by dimethylhydrazine. Zhonghua Yu Fang Yi Xue Za Zhi 29, 13-17.

Chen, H. B., Wu, J. Y., Wang, C. F., Fu, C. C., Shieh, C. J., Chen, C. I., et al. (2010). Modeling on chlorophyll a and phycocyanin production by Spirulina platensis under various light-emitting diodes. Biochem. Eng. J. 53, 52-56. doi: 10.1016/j.bej.2010.09.004

Chen, H. W., Yang, T. S., Chen, M. J., Chang, Y. C., Wang, E. I. C., Lai, C. L., et al. (2014). Purification and immunomodulating activity of C-phycocyanin from Spirulina platensis cultured using power plant flue gas. Proc. Biochem. 49, 1337-1344. doi: 10.1016/j.procbio.2014.05.006

Chen, T., and Wong, Y. S. (2008). In vitro antioxidant and antiproliferative activities of selenium-containing phycocyanin from selenium-enriched Spirulina platensis. J. Agric. Food Chem. 56, 4352-4358. doi: 10.1021/jf0 73399k

Chen, W. T., Yang, T. S., Chen, H. C., Chen, H. H., Chiang, H. C., Lin, T. C., et al. (2014). Effectiveness of a novel herbal agent MB-6 as a potential adjunct to 5-fluoracil-based chemotherapy in colorectal cancer. Nutr. Res. 34, 585-594. doi: 10.1016/j.nutres.2014.06.010

Choi, G. G., Bae, M. S., Ahn, C. Y., and Oh, H. M. (2008). Enhanced biomass and gamma-linolenic acid production of mutant strain Arthrospira platensis. J. Microbiol. Biotechnol. 18, 539-544.

Chojnacka, K., and Noworyta, A. (2004). Evaluation of Spirulina sp. growth in photoautotrophic, heterotrophic and mixotrophic cultures. Enzyme Microb. Technol. 34, 461-465. doi: 10.1016/j.enzmictec.2003.12.002

Ciferri, O. (1983). Spirulina, the edible microorganism. Microbiol. Rev. 47, 551-578.

Cohen, Z., and Vonshak, A. (1991). Fatty acid composition of Spirulina and Spirulina-like cyanobacteria in relation to their chemotaxonomy. Phytochemisty 30, 205-206. doi: 10.1016/0031-9422(91)84125-C

Comte, K., Coursin, T., and Carre-Mlouka, A. (2013). A new genotype in the genus Arthrospira (Oscillatoriales, Cyanobacteria) revealed by a mosaic-like structure of the 16S-23SrRNA intergenic spacer region in strain PCC 9901. Phycologia 52, 333-337. doi: 10.2216/12-063.1

Converti, A., Lodi, A., Del Borghi, A., and Solisio, C. (2006). Cultivation of Spirulina platensis in a combined airlift-tubular reactor system. Biochem. Eng. J. 32, 13-18. doi: 10.1016/j.bej.2006.08.013

Costa, J. A. V., Colla, L. M., and Duarte Filho, P. (2003). Spirulina platensis growth in open raceway ponds using fresh water supplemented with carbon, nitrogen and metal ions. Z. Naturforsch. C. 58, 76-80. doi: 10.1515/znc-2003-1-214

Credentials|Abundance (2017). Abundance.co.il. Available online at: http:// abundance.co.il/en/89 (Accessed January 24, 2017).

Dadheech, P. K., Ballot, A., Casper, P., Kotut, K., Novelo, E., Lemma, B., et al. (2010). Phylogenetic relationship and divergence among planktonic strains of Arthrospira (Oscillatoriales, Cyanobacteria) of African, Asian and American origin deduced by 16S-23S ITS and phycocyanin operon sequences. Phycologia 49, 361-372. doi: 10.2216/09-71.1
Dai, G. Z., Giu, B. S., and Forchhammer, K. (2014). Ammonium tolerance in the cyanobacterium Synechocystis sp. strain PCC 6803 and the role of the psbA multigene family. Plant Cell Environ. 37, 840-851. doi: 10.1111/pce.12202

Danesi, E. D. G., de Rangel-Yagui, C. O., de Carvalho, J. C. M., and Sato, S. (2002). An investigation of effect of replacing nitrate by urea in the growth and production of chlorophyll by Spirulina platensis. Biomass Bioenergy 23, 261-269. doi: 10.1016/S0961-9534(02)00054-5

Dartsch, P. C. (2008). Antioxidant potential of selected Spirulina platensis preparations. Phytother. Res. 22, 627-633. doi: 10.1002/ptr.2310

de Jesus Raposo, M. F., de Morais, R. M., and de Morais, A. M. (2013). Health applications of bioactive compounds from marine microalgae. Life Sci. 93, 479-486. doi: 10.1016/j.lfs.2013.08.002

de Morais, M. G., Stillings, C., Dersch, R., Rudisile, M., Pranke, P., Costa, J. A., et al. (2010). Preparations of nanofibers containing the microalga Spirulina (Arthrospira). Bioresour. Technol. 101, 2872-2876. doi: 10.1016/j.biortech.2009.11.059

de Morais, M. G., Vaz, B. S., Morais, E. G., and Costa, J. A. V. (2014). Biological effects of Spirulina (Arthrospira) biopolymers and biomass in the development of nanostructured scaffolds. BioMed. Res. Intern. 2014, 1-9. doi: 10.1155/2014/762705

De Philippis, R., and Vincenzini, M. (1998). Exocellular polysaccharides from cyanobacteria and their possible applications. FEMS Microbiol. Rev. 22, 151-175. doi: 10.1111/j.1574-6976.1998.tb00365.x

Deng, R., and Chow, T.-J. (2010). Hypolipidemic, antioxidant and antiinflammatory activities of microalgae Spirulina. Cardiovasc. Ther. 28, e33-e45. doi: 10.1111/j.1755-5922.2010.00200.x

Depraetere, O., Deschoenmaeker, F., Badri, H., Monsieurs, P., Foubert, I., Leys, N., et al. (2015). Trade-off between growth and carbohydrate accumulation in nutrient limited Arthrospira sp. PCC 8005 studied by integrating transcriptome and proteomic approaches. PLOS ONE 10:e0132461. doi: 10.1371/journal.pone.0132461

Deschoenmaeker, F., Facchini, R., Leroy, B., Badri, H., Zhang, C. C., and Wattiez, R. (2014). Proteomic and cellular views of Arthrospira sp. PCC 8005 adaptation to nitrogen depletion. Microbiology 160, 1224-1236. doi: 10.1099/mic.0.074641-0

Desikachary, T. V., and Jeeji Bai, N. (1992). "Taxonomic studies in Spirulina," in SESHARDI, ETTA National Symposium, eds C. V. Seshardi andN. Jeeji Bai (Madras: MCRC), 12-21.

Desikachary, T. V., and Jeeji Bai, N. (1996). Taxonomic studies in Spirulina, II. The identification of Arthrospira ("Spirulina") strains and natural samples of different geographical origins. Algolog. Stud. 83, 163-178.

Dong, S., Chen, J., Wang, S., Wu, Y., Hou, H., Li, M., et al. (2015). Draft genome sequence of cyanobacteria Arthrospira sp. TJSD091 isolated from seaside wetland. Mar. Genomics 24, 197-198. doi: 10.1016/j.margen.2015.05.008

Donia, M. S., and Schmidt, E. W. (2011). Linking chemistry and genetics in the growing cyanobactin natural products family. Chem. Biol. 18, 508-519. doi: 10.1016/j.chembiol.2011.01.019

Duda-Chodak, A. (2013). Impact of water extracts of Spirulina (WES) on bacteria, yeasts and molds. Acta Sci. Pol. Technol. Aliment. 12, 33-39.

El-Sheekh, M. M., and El-Kassas, H. Y. (2014). Application of biosynthesized silver nanoparticles against a cancer promoter cyanobacterium, Microcystis aeruginosa. Asian Pac. J. Cancer Prev. 15, 6773-6779. doi: 10.7314/APJCP.2014.15.16.6773

Falquet, J., Hurni, J.P. (1997). The Nutritional Aspects of Spirulina. Antenna Foundation. Available online at: https:/www.antenna.ch/wp-content/uploads/ 2017/03/AspectNut_UK.pdf (Accessed July 25, 2017)

FAO (2016). The State of World Fisheries and Aquaculture 2016. Contributing to Food Security and Nutrition for All. Rome, 200.

FDA (2002). Agency Response Letter GRAS Notice No., GRN 000101 (2002). Fda.gov. Available online at: http://www.fda.gov/Food/ IngredientsPackagingLabeling/GRAS/NoticeInventory/ucm153674.htm (Accessed January 24, 2017).

Feng, D. L., and Wu, Z. C. (2006). Culfnnfure of Spirulina platensis in human urine for biomass production and $\mathrm{O}_{2}$ evolution. J. Zhejiang Univ. Sci. B 7, 34-37. doi: 10.1631/jzus.2006.B0034

Fevrier, C., and Seve, B. (1975). Incorporation of a spiruline (Spirulina maxima) in swine food. Ann. Nutr. Aliment. 29, 625-650. 
Fujisawa, T., Narikawa, R., Okamoto, S., Ehira, S., Yoshimura, H., Suzuki, I., et al. (2010). Genomic structure of an economically important Cyanobacterium, Arthrospira (Spirulina) platensis NIES-39. DNA Res. 17, 85-103. doi: 10.1093/dnares/dsq004

Furrer, E. M., Ronchetti, M. F., Verrey, F., and Pos, K. M. (2007). Functional characterization of a $\mathrm{NapA} \mathrm{Na}(+) / \mathrm{H}(+)$ antiporter from Thermus thermophiles. FEBS Lett. 6:581. doi: 10.1016/j.febslet.2006.12.059

Gao, K., and Ma, Z. (2008). Photosynthesis and growth of Arthrospira (Spirulina) platensis (Cyanophyta) in response to solar UV radiation, with special reference to its minor variant. Environ. Exp. Bot. 63, 123-129. doi: 10.1016/j.envexpbot.2007.10.031

Gao, K., Li, P., Watanabe, T., and Helbling, W. E. (2008). Combined effects of ultraviolet radiation and temperature on morphology, photosynthesis, and DNA of Arthrospira (Spirulina) platensis (Cyanophyta). J. Phycol. 44, 777-786. doi: 10.1111/j.1529-8817.2008.00512.x

Geitler, L. (1932). "Cyanophyceae” in Kryptogamen-Flora von Deutschland, Vol. 14, ed L. Rabenhorst (Leipzig: Akademische Verlagsgesellschaft), 673-1196.

Gemma, C., Mesches, M. H., Sepesi, B., Choo, K., Holmes, D. B., and Bickford, P. C. (2002). Diets enriched in foods with high antioxidant activity reverse age-induced decreases in cerebellar beta-adrenergic function and increases in proinflammatory cytokines. J. Neurosci. 22, 6114-6120.

Gilles, R., and Gilles-Baillien, M. (1985). Transport Processes, Iono- and Osmoregulation. Current Comparative Approaches. Berlin; Heidelberg: Springer.

Gòdia, F., Albiol, J., Montesinos, J. L., Perez, J., Creus, N., Cabello, F., et al. (2002). MELISSA: a loop of interconnected bioreactors to develop life support in Space. J. Biotechnol. 99, 319-330. doi: 10.1016/S0168-1656(02)00222-5

Gorobets, O. B., Blinkova, L. P., and Baturo, A. P. (2002). Action of Spirulina platensis on bacterial viruses. Zh. Mikrobiol. Epidemiol. Immunobiol. 18-21.

Guglielmi, G., Rippka, R., and Tandeau de Marsac, N. (1993). Main properties to justify the different taxonomic position of Spirulina spp. and Arthrospira spp. among Cyanobacteria. Bull. Inst. Oceanogr. Monaco 12:13.

Habib, M. A. B., Pariv, M., Huntington, T. C., and Hasan, M. R. (2008). A Review on Culture, Production and Use of Spirulina as Food for Humans and Feeds for Domestic Animals and Fish. FAO Fisheries and Aquaculture Circular No. (1034). Food and Agriculture Organization (FAO) of the United Nations, Rome.

Hagemann, M. (2010). Molecular biology of cyanobacterial salt acclimation. FEMS Microbiol. Rev. 35, 87-123. doi: 10.1111/j.1574-6976.2010.00234.x

Hagemann, M. (2013). "Genomics of salt acclimation: synthesis of compatible solutes among Cyanobacteria," in Genomics of Cyanobacteria, eds F. Chauvat and C. Cassier-Chauvat (Oxford: Academic Press), 27-55.

Han, L. K., Li, D. X., Xiang, L., Gong, X. J., Kondo, Y., Suzuki, I., et al. (2006). Isolation of pancreatic lipase activity-inhibitory component of Spirulina platensis and it reduce postprandial triacylglycerolemia. Yakugaku Zasshi 126, 43-49. doi: 10.1248/yakushi.126.43

Hayashi, T., Hayashi, K., Maeda, M., and Kojima, I. (1996). Calcium spirulan, an inhibitor of enveloped virus replication, from a blue-green alga Spirulina platensis. J. Nat. Prod. 59, 83-87. doi: 10.1021/np960017o

Helbling, E. W., Gao, K., Ai, H., Ma, Z., and Villafane, V. E. (2006). Differential responses of Nostoc sphaeroides and Arthrospira platensis to solar ultraviolet radiation exposure. J. Appl. Phycol. 18, 57-66. doi: 10.1007/s10811-0059015-5

Hendrickx, L., De Wever, H., Hermans, V., Mastroleo, F., Morin, N., Wilmotte, A., et al. (2006). Microbial ecology of the closed artificial ecosystem MELiSSA (Micro-Ecological Life Support System Alternative): reinventing and compartmentalizing the Earth's food and oxygen regeneration system for long-haul space exploration missions. Res. Microbiol. 157, 77-86. doi: 10.1016/j.resmic.2005.06.014

Herdman, M., Janvier, M., Waterbury, J. B., Rippka, R., Stanier, R. Y., and Mandel, M. (1979). Deoxyribonucleic acid base composition of cyanobacteria. J. Gen. Micobiol. 111:63. doi: 10.1099/00221287-111-1-63

Hernández-Corona, A., Nieves, I., Meckes, M., Chamorro, G., and Barron, B. L. (2002). Antiviral activity of Spirulina maxima against herpes simplex virus type 2. Antiviral. Res. 56, 279-285. doi: 10.1016/S0166-3542(02)00132-8

Hoiczyk, E., and Baumeister, W. (1997). Oscillin, an extracellular $\mathrm{Ca}^{2+}$-bingind glycoprotein essential for the gliding motility of cyanobacteria. Mol. Microbiol. 26, 699-708. doi: 10.1046/j.1365-2958.1997.5971972.x
Huili, W., Xiaokai, Z., Meili, L., Dahlgren, R. A., Wei, C., Jaiopeng, Z., et al. (2013). Proteomic analysis and qRT-PCR verification of temperature response to Arthrospira (Spirulina) platensis. PLoS ONE 8:e83485. doi: 10.1371/journal.pone.0083485

Iliev, I., Petkov, G., Lukavsky, J., Furnadzhiev, S., and Andreeva, R. (2011). Do cyanobacterial lipids contain fatty acids longer than 18 carbon atoms? $Z$. Naturforsch. C 66, 267-276. doi: 10.5560/ZNC.2011.66c0267

Jacquet, S., Zhong, X., Parvathi, A., and Ram, A. S. P. (2013). First description of cyanophage infecting the cyanobacterium Arthrospira platensis (Spirulina). J. Appl. Phycol. 25, 195-203. doi: 10.1007/s10811-012-9853-x

Janssen, P. J., Morin, N., Mergeay, M., Leroy, B., Wattiez, R., Vallaeys, T., et al. (2010). Genome sequence of the edible Cyanobacterium Arthrospira sp. PCC 8005. J. Bacteriol. 192, 2465-2466. doi: 10.1128/JB.00116-10

Jau, M.-H., Yew, S.-P., Toh, P. S. Y., Chong, A. S. C., Chu, W.-L., Phang, S.M., et al. (2005). Biosynthesis and mobilization of poly(3-hydroxybutyrate) $[\mathrm{P}(3 \mathrm{HB})]$ by Spirulina platensis. Int. J. Biol. Macromol. 36, 144-151. doi: 10.1016/j.ijbiomac.2005.05.002

Jeamton, W., Dulsawat, S., Tanticharoen, M., Vonshak, A., and Cheevadhanarak, S. (2017). Overcoming intristic restriction enzyme barriers enhances transformation efficiency in Arthrospira platensis C1. Plant Cell Physiol. 58, 822-830. doi: 10.1093/pcp/pcx016

Jeeji Bai, N. (1985). Competitive exclusion or morphological transformation? A cesestudy with Spirulina fusiformis. Algol Stud. 38/39, 191.

Jeeji Bai, N., and Seshadri, C. N. (1980). On coiling and uncoiling of trichomes in the genus Spirulina. Algol Stud. 26, 32-47.

Juantorena, A. U., Sebastian, P. J., Santoyo, E., Gamboa, S. A., Lastres, O. D., Sanchez-Escamilla, D., et al. (2007). Hydrogen production employing Spirulina maxima 2342: A chemical analysis. Int. J. Hydrogen Eng. 32, 3133-3136. doi: 10.1016/j.ijhydene.2006.02.033

Jubie, S., Dhanabal, S. P., and Chaitanya, M. V. (2015). Isolation of methyl gamma linolenate from Spirulina platensis using flash chromatography and its apoptosis inducing effect. BMC Complement. Altern. Med. 15:263. doi: 10.1186/s12906-015-0771-8

Kaggwa, M. N., Burian, A., Oduor, S. O., and Schagerl, M. (2013). Ecomorphological variability of Arthrospira fusiformis (Cyanoprokaryota) in African soda lakes. Microbiologyopen 2, 881-891. doi: 10.1002/ mbo3.125

Kawanishi, Y., Tominaga, A., Okuyama, H., Fukuoka, S., Taguchi, T., Kusumoto, Y., et al. (2013). Regulatory effects of Spirulina complex polysaccharides on growth of murine RSV-M glioma cells through Toll-like receptor 4. Microbiol. Immunol. 57, 63-73. doi: 10.1111/1348-0421.12001

Kawata, Y., Yano, S., and Kojima, H. (1998). Efficient library construction with a TA vector and its application to cloning of the phytoene synthase gene from the cyanobacterium Spirulina platensis. Curr. Microbiol. 37, 289-291. doi: $10.1007 / \mathrm{s} 002849900380$

Kawata, Y., Yano, S., Kojima, H., and Toyomizu, M. (2004). Transformation of Spirulina platensis strain C1 (Arthrospira sp. PCC9438) with Tn5 transposasetransposon DNA-cation liposome complex. Mar. Biotechnol. 6, 355-363. doi: $10.1007 /$ s10126-003-0037-1

Khan, M., Shobha, J. C., Mohan, I. K., Naidu, M. U., Sundaram, C., Singh, S., et al. (2005). Protective effect of Spirulina against doxorubicin-induced cardiotoxicity. Phytother. Res. 19, 1030-1037. doi: 10.1002/ptr.1783

Khan, M., Varadharaj, S., Shobha, J. C., Naidu, M. U., Parinandi, N. L., Kutala, V. K., et al. (2006). C-phycocyanin ameliorates doxorubicin-induced oxidative stress and apoptosis in adult rat cardiomyocytes. J. Cardiovasc. Pharmacol. 47, 9-20. doi: 10.1097/01.fjc.0000191520.48404.27

Khan, Z., Bhadouria, P., and Bisen, P. S. (2005). Nutritional and therapeutic potential of Spirulina. Curr. Pharm. Biotechnol. 6, 373-379. doi: 10.2174/138920105774370607

Kim, W., and Lee, K. G. (2013). Lead and cadmium in functional health foods and Korean herbal medicines. Food Addit. Contam. Part B Surveill. 6, 146-149. doi: 10.1080/19393210.2013.769026

Kiziltan, H. S., Gunes Bayir, A., Taspinar, O., Yucesan, G., Tastekin, D., Sonmez, F. C., et al. (2015). Radioprotectant and cytotoxic effects of Spirulina in relapsed verrucous vulvar cancer: a case report. Altern. Ther. Health Med. 21, 68-72.

Komárek, J., and Anagnostidis, K. (2005). “Cyanoprokaryota: Oscillatoriales," in Süsswasserflora von Mitteleuropa 19/2, eds B. Büdel, L. Krienitz, G. Gärtner, and M. Schagerl (Heidelberg: Elsevier/Spektrum), 1-759. 
Konícková, R., Vanková, K., Vaníková, J., Vánová, K., Muchová, L., Subhanová, I., et al. (2014). Anti-cancer effects of blue-green alga Spirulina platensis, a natural source of bilirubin-like tetrapyrrolic compounds. Ann. Hepatol. 13, 273-283.

Kordowska-Wiater, M., Wasko, A., Polak-Berecka, M., Kubik-Komar, A., and Targonski, Z. (2011). Spirulina enhances the viability of Lactobacillus rhamnosus $\mathrm{E} / \mathrm{N}$ after freeze-drying in a protective medium of sucrose and lactulose. Lett. Appl. Microbiol. 53, 79-83. doi: 10.1111/j.1472-765X.2011.03068.x

Kuhad, A., Tirkey, N., Pilkhwal, S., and Chopra, K. (2006a). Effect of Spirulina, a blue green algae, on gentamicin-induced oxidative stress and renal dysfunction in rats. Fundam. Clin. Pharmacol. 20, 121-128. doi: 10.1111/j.1472-8206.2006.00396.x

Kuhad, A., Tirkey, N., Pilkhwal, S., and Chopra, K. (2006b). Renoprotective effect of Spirulina fusiformis on cisplatin-induced oxidative stress and renal dysfunction in rats. Ren. Fail. 28, 247-254. doi: 10.1080/08860220600580399

Kumar, M., Kulshreshtha, J., and Singh, G. P. (2011). Growth and biopigment accumulation of cyanobacterium Spirulina platensis at different light intensities and temperature. Braz. J. Microbiol. 42, 1128-1135. doi: 10.1590/S1517-83822011000300034

Kumerasan, V., Nizam, F., Ravichandran, G., Viswanathan, K., Palanisamy, R., Bhatt, P., et al. (2017). Transcriptome changes of blue-green algae, Arthrospira sp. in response to sulfate stress. Algal Res. 23, 96-103. doi: 10.1016/j.algal.2017.01.012

Kurd, F., and Samavati, V. (2015). Water soluble polysaccharides from Spirulina platensis: extraction and in vitro anti-cancer activity. Int. J. Biol. Macromol. 74, 498-506. doi: 10.1016/j.ijbiomac.2015.01.005

Lee, J. B., Hayashi, T., Hayashi, K., and Sankawa, U. (2000). Structural analysis of calcium spirulan (Ca-SP)-derived oligosaccharides using electrospray Ioiization mass spectrometry. J. Nat. Prod.. 63, 136-138. doi: $10.1021 / \mathrm{np} 990348 \mathrm{~b}$

Lee, J. B., Hayashi, T., Hayashi, K., Sankawa, U., Maeda, M., Nemoto, T., et al. (1998). Further purification and structural analysis of calcium spirulan from Spirulina platensis. J. Nat. Prod. 61, 1101-1104. doi: 10.1021/np980143n

Lefort, F., Calmin, G., Crovadore, J., Falquet, J., Hurni, J., Osteras, M., et al. (2014). Whole-genome shotgun sequence of Arthrospira platensis strain Paraca, a cultivated and edible cyanobacterium. Genome Announc. 2:e00751-e00714. doi: 10.1128/genomeA.00751-14

Leonard, J., and Compere, P. (1967). Spirulina platensis(Gom.) Geitl., algue bleue de grande valeur alimentaire par sa richeseen proteins. Bull. Jard. Bot. Nat. Belg. $37,3-23$.

Lewin, R. A. (1980). Uncoiled variants of Spirulina platensis (Cyanophyceae: Oscillatoriaceae). Arch. Hydrobiol. 26, 48-52.

Li, B., Chu, X.-M., Xu, Y.-J., Yang, F., Lv, C.-Y., and Nie, S.-M. (2013). CD59 underlines the antiatherosclerotic effects of C-phycocyanin on mice. BioMed. Res. Intern. 15:729413. doi: 10.1155/2013/729413

Li, B., Gao, M. H., Zhang, X. C., and Chu, X. M. (2006). Molecular immune mechanism of C-phycocyanin from Spirulina platensis induces apoptosis in HeLa cells in vitro. Biotechnol. Appl. Biochem. 43, 155-164. doi: 10.1042/BA20050142

Lim, B. J., Jeong, J. Y., Chang, J. K., Na, K. R., Lee, K. W., Shin, Y. T., et al. (2012). $\mathrm{C}$-phycocyanin attenuates cisplatin-induced nephrotoxicity in mice. Ren. Fail. 34, 892-900. doi: 10.3109/0886022X.2012.690925

Linhartová, I., Bumba, L., Masin, J., Basler, M., Osicka, R., Kamanova, J., et al. (2010). RTX proteins: a highly diverse family secreted by a common mechanism. FEMS Microbiol. Rev. 34, 1076-1112. doi: 10.1111/j.1574-6976.2010.00231.x

Løbner, M., Walsted, A., Larsen, R., Bendtzen, K., and Nielsen, C. H. (2008). Enhancement of human adaptive immune responses by administration of a high-molecular-weight polysaccharide extract from the cyanobacterium Arthrospira platensis. J. Med. Food 11, 313-322. doi: 10.1089/jmf.2007.564

Madhyastha, H. K., and Vatsala, T. M. (2007). Pigment production in Spirulina fussiformis in different photophysical conditions. Biomol. Eng. 24, 301-305. doi: 10.1016/j.bioeng.2007.04.001

Mala, R., Sarojini, M., Saravanababu, S., and Umadevi, G. (2009). Screening of antimicrobial activity of crude extracts of Spirulina platensis. J. Cell Tissue Res. 9, 1951-1955.

Manen, J.-F., and Falquet, J. (2002). The $c p c B-c p c A$ locus as a tool for the genetic characterization of the genus Arthrospira (Cyanobacteria): evidence for horizontal transfer. Int. J. Syst. Evol. Microbiol. 52, 861-867. doi: 10.1099/00207713-52-3-861

Mao, T. K., Van De Water, J., and Gershwin, M. E. (2000). Effect of spirulina on the secretion of cytokines from peripheral blood mononuclear cells. J. Med. Food 3, 135-140. doi: 10.1089/jmf.2000.3.135

Mao, T. K., Van de Water, J., and Gershwin, M. E. (2005). Effects of a Spirulinabased dietary supplement on cytokine production from allergic rhinitis patients. J. Med. Food 8, 27-30. doi: 10.1089/jmf.2005.8.27

Markou, G. (2014). Effect of various colors of light-emitting diodes (LEDs) on the biomass composition of Arthrospira platensis cultivated in semi-continuous mode. Appl. Biochem. Biotechnol. 172, 2758-2768. doi: 10.1007/s12010-014-0727-3

Markou, G., Chatzipavlidis, I., and Georgakakis, D. (2012). Effects of phosphorus concentration and light intensity on the biomass composition of Arthrospira (Spirulina) platensis. World J. Microbiol. Biotechnol. 28, 2661-2670. doi: 10.1007/s11274-012-1076-4

Markou, G., Vandamme, D., and Muylaert, K. (2014). Ammonia inhibition on Arthrospira platensis in relation to the initial biomass density and $\mathrm{pH}$. Bioresour. Technol. 166, 259-265. doi: 10.1016/j.biortech.2014.05.040

Marles, R. J., Barrett, M. L., Barnes, J., Chavez, M. L., Gardiner, P., Ko, R., et al. (2011). United States pharmacopeia safety evaluation of spirulina. Crit. Rev. Food Sci. Nutr. 51, 593-604. doi: 10.1080/10408391003721719

Marquez, F. J., Sasaki, K., Kakizono, T., Nishio, N., and Nagai, S. (1993). Growth characteristics of Spirulina platensis in mixotrophic and heterotrophic conditions. J. Ferment. Bioeng. 76, 408-410. doi: 10.1016/0922-338X(93)90034-6

Martins, J., Leao, P. N., Ramos, V., and Vasconcelos, V. (2013). N-terminal protease gene phylogeny reveals the potential for novel cyanobactin diversity in Cyanobacteria. Mar. Drugs 11, 4902-4916. doi: 10.3390/md11124902

Matallana-Surget, S., Derock, J., Leroy, B., Badri, H., Deschoenmaeker, F., and Wattiez, R. (2014). Proteome-wide analysis and diel proteomic profiling of the cyanobacterium Arthrospira platensis PCC8005. PLoS ONE 9:e99076. doi: 10.1371/journal.pone.0099076

Materassi, R., Tredici, M., and Balloni, W. (1984). Spirulina culture in sea-water. Appl. Microbiol. Biotechnol. 19, 384-386. doi: 10.1007/BF00454374

Mathew, B., Sankaranarayanan, R., Nair, P. P., Varghese, C., Somanathan, T., Amma, B. P., et al. (1995). Evaluation of chemoprevention of oral cancer with Spirulina fusiformis. Nutr. Cancer 24, 197-202. doi: 10.1080/01635589509514407

McCarty, M. F. (2010). Practical prevention of cardiac remodeling and atrial fibrillation with full-spectrum antioxidant therapy and ancillary strategies. Med. Hypotheses 75, 141-147. doi: 10.1016/j.mehy.2009.12.025

McCarty, M. F. (2013). Nutraceutical strategies for ameliorating the toxic effects of alcohol. Med. Hypotheses 80, 456-462. doi: 10.1016/j.mehy.2012.12.040

McCarty, M. F., O’Keefe, J. H., and DiNicolantonio, J. J. (2015). Carvedilol and spirulina may provide important health protection to smokers and other nicotine addicts: a call for pertinent research. Mo. Med. 112, 72-75.

Miklaszewska, M., Waleron, M., and Waleron, K. (2008a). Biotechnological potential of the cyanobacteria from Arthrospira genus. Biotechnologia 3, 119-142.

Miklaszewska, M., Waleron, M., and Waleron, K. (2008b). Characteristics of the edible cyjanobacteria from Arthrospira genus. Biotechnologia 3, 103-118.

Miklaszewska, M., Waleron, M., Morin, N., Całusinska, M., Wilmotte, A., Tandeau De Marsac, N., et al. (2012). Elucidation of the gas vesicle gene clusters in cyanobacteria of the genus Arthrospira (Oscillatoriales, Cyanophyta) and correlation with ITS phylogeny. Eur. J. Phycol. 47, 233-244. doi: 10.1080/09670262.2012.692817

Mishima, T., Murata, J., Toyoshima, M., Fujii, H., Nakajima, M., Hayashi, T., et al. (1998). Inhibition of tumor invasion and metastasis by calcium spirulan (Ca-SP), a novel sulfated polysaccharide derived from a blue-green alga, Spirulina platensis. Clin. Exp. Metastasis 16, 541-550. doi: 10.1023/A:100659 4318633

Moraes, I. D. O., Arruda, R. D. O. M., Maresca, N. R., Antunes, A. D. O., and Moraes, R. D. O. (2013). Spirulina platensis: process optimization to obtain biomass. Food Sci. Techmol. 33, 179-183. doi: 10.1590/S0101-20612013000500026

Morin, N., Vallayes, T., Hendrickx, L., Natalie, L., and Wilmotte, A. (2010). An efficient DNA isolation protocol for filamentous cyanobacteria 
of the genus Arthrospira. J. Microbiol. Methods. 80, 148-154. doi: 10.1016/j.mimet.2009.11.012

Muhling, M., Belay, A., and Whitton, B. (2005). Screening Arthrospira (Spirulina) strains for heterotrophy. J. Appl. Phycol. 17, 129-135. doi: $10.1007 /$ s10811-005-7214-8

Murata, N., Deshnium, P., and Tasaka, Y. (1996). "Biosynthesis of gamma-linolenic acid in the cyanobacterium Spirulina platensis," in Gamma-linolenic Acid: Metabolism and Its Roles in Nutrition and Medicine, 1st Edn, eds Y. S. Huang and D. E Mills (San Antonio, TX: AOCS Press; Urbana-Champaign), 22-32.

Nagaoka, S., Shimizu, K., Kaneko, H., Shibayama, F., Morikawa, K., Kanamaru, Y., et al. (2005). A novel protein C-phycocyanin plays a crucial role in the hypocholesterolemic action of Spirulina platensis concentrate in rats. J. Nutr. $135,2425-2430$.

Najdenski, H. M., Gigova, L. G., Iliev, I. I., Pilarski, P.S., Lukavský, J., Tsvetkova, I. V., et al. (2013). Antibacterial and antifungal activities of selected microalgae and cyanobacteria. Int. J. Food Sci. Technol. 48, 1533-1540. doi: $10.1111 /$ ijfs. 12122

Naturalways (2017) "Spirulina's Nutritional Analysis." Available online at: http://www.naturalways.com/nutritional-research.htm (Accessed December 12, 2017).

Nelissen, B., Wilmotte, A., Neefs, J. M., and De Watcher, R. (1994). Phylogenetic relationships among filamentous helical cyanobacteria investigated on the basis of $16 \mathrm{~S}$ ribosomal RNA gene sequence analysis. Syst. Appl. Microbiol. 17, 206-210. doi: 10.1016/S0723-2020(11)80009-3

Nemoto-Kawamura, C., Hirahashi, T., Nagai, T., Yamada, H., Katoh, T., and Hayashi, O. (2004). Phycocyanin enhances secretary IgA antibody response and suppresses allergic IgE antibody response in mice immunized with antigenentrapped biodegradable microparticles. J. Nutr. Sci. Vitaminol. 50, 129-136. doi: $10.3177 /$ jnsv. 50.129

Nielsen, C. H., Balachandran, P., Christensen, O., Pugh, N. D., Tamta, H., Sufka, K. J., et al. (2010). Enhancement of natural killer cell activity in healthy subjects by Immulina ${ }^{\circledR}$, a Spirulina extract enriched for Braun-type lipoproteins. Planta Med. 76,1802-1808. doi: 10.1055/s-0030-1250043

Ogato, T., Kifle, D., Fetahi, T., and Sitotaw, B. (2014). Evaluation of growth and biomass production of Arthrospira (Spirulina) fusiformis in laboratory cultures using waters from the Ethiopian soda lakes Chitu and Shala. J. Appl. Phycol. 26, 2273-2282. doi: 10.1007/s10811-014-0251-4

Olguín, E. J., Galicia, S., Angulo-Guerrero, O., and Hernández, E. (2001). The effect of low light flux and nitrogen deficiency on the chemical composition of Spirulina sp. (Arthrospira) grown on digested pig waste. Bioresour. Technol. 77, 19-24. doi: 10.1016/S0960-8524(00)00142-5

Ouhtit, A., Ismail, M. F., Othman, A., Fernando, A., Abdraboh, M. E., El-Kott, A. F., et al. (2014). Chemoprevention of rat mammary carcinogenesis by spirulina. Am. J. Pathol. 184, 296-303. doi: 10.1016/j.ajpath.2013.10.025

Pabon, M. M., Jernberg, J. N., Morganti, J., Contreras, J., Hudson, Ch., Klein, R. L., et al. (2012). A spirulina-enhanced diet provides neuroprotection in an $\alpha$-synuclein model of Parkinson's Disease. PLoS ONE 7:e45256. doi: 10.1371/journal.pone.0045256

Pan, R., Lu, R., Zhang, Y., Zhu, M., Zhu, W., Yang, R., et al. (2015). Spirulina phycocyanin induces differential protein expression and apoptosis in SKOV-3 cells. Int. J. Biol. Macromol. 81, 951-959. doi: 10.1016/j.ijbiomac.2015.09.039

Panyakampol, J., Cheevadhanarak, S., Sutheeworapong, S., Chaijaruwanich, J., Senchak, J., Siangdung, W., et al. (2014). Physiological and transcriptional responses to high temperature in Arthrospira (Spirulina) platensis C1. Plant Cell Physiol. 56. 481-496. doi: 10.1093/pcp/pcu192

Parada, J. L., Zulpa de Caire, G., Zaccaro de Mule, M. C., and Storni de Cano, M. M. (1998). Lactic acid bacteria growth promoters from Spirulina platensis. Int. J. Food Microbiol. 45, 225-228. doi: 10.1016/S0168-1605(98)00151-2

Peduzzi, P., Gruber, M., Gruber, M., and Schagerl, M. (2014). The virus's tooth: cyanophages affect an African flamingo population in a bottom-up cascade. ISME J. 8, 1346-1351. doi: 10.1038/ismej.2013.241

Pelizer, L. H., and Moraes, I. O. (2009). Development of solid state cultivation for Spirulina platensis production. New Biotechnol. 25, 223-224. doi: 10.1016/j.nbt.2009.06.189

Pervushkin, S. V., Voronin, A. V., Kurkin, V. A., Sokhina, A. A., and Shatalaev, I. F. (2001). Proteins from Spirulina platensis biomass. Chem. Nat. Comp. 37, 476-481. doi: 10.1023/A:1014435813520
Pingoud, A., and Jeltsch, A. (2001). Structure and function of type II restriction endonucleases. Nucleic Acids Res. 29, 3705-3727. doi: 10.1093/nar/29. 18.3705

Pradhan, J., Das, B. K., Sahu, S., Marhual, N. P., Swain, A. K., Mishra, B. K., et al. (2011). Traditional antibacterial activity of freshwater microalga Spirulina platensis to aquatic pathogens. Aquacult. Res. 43, 1287-1295. doi: $10.1111 / j .1365-2109.2011 .02932 . x$

Pulz, O., and Gross, W. (2004). Valuable products from biotechnology of microalgae. Appl. Microbiol. Biotechnol. 65. 635-648. doi: 10.1007/s00253-004-1647-x

Puyfoulhoux, G., Rouanet, J.-M., Besançon, P., Baroux, B., Baccou, J.-C., and Caporiccio, B. (2001). Iron availability from iron-fortified spirulina by an in vitro digestion/Caco-2 cell culture model. J. Agric. Food Chem. 49, 1625-1629. doi: $10.1021 / \mathrm{jf} 001193 \mathrm{c}$

Quereshi, M. A., Ali, R. A., and Hunter, R. (1995). "Immuno-modulatory effects of Spirulina platensis supplementation in chickens" in Proceedings of the 44th Western Poultry Disease Conference (Sacramento, CA), 117-121.

Qureshi, M. A., Garlich, J. D., and Kidd, M. T. (1996). Dietary Spirulina platensis enhances humoral and cell-mediated immune functions in chickens. Immunopharmacol. Immunotoxicol. 18, 465-476.

Rakhimberdieva, M. G., Stadnichuk, I. N., Elanskaya, I. V., and Karapetyan, N. V. (2004). Carotenoid-induced quenching of the phycobilisome fluorescence in photosystem II-deficient mutant of Synechocystis sp. FEBS Lett. 574, 85-88. doi: 10.1016/j.febslet.2004.07.087

Raksajit, W., Satchasataporn, K., Lehto, K., Mäenpää, P., and Incharoensakdi, A. (2012). Enhancement of hydrogen production by the filamentous nonheterocystous cyanobacterium Arthrospira sp. PCC 8005. Int. J. Hydrogen Energy. 37, 18791-18797. doi: 10.1016/j.ijhydene.2012.10.011

Rastogi, R. P., and Incharoensakdi, A. (2014). Analysis of UV-absorbing photoprotectant mycosporine-like amino acid (MAA) in the cyanobacterium Arthrospira sp. CU2556. Photochem. Photobiol. Sci. 13, 1016-1024. doi: $10.1039 / \mathrm{c} 4 \mathrm{pp} 00013 \mathrm{~g}$

Ravelonandro, P. H., Ratianarivo, D. H., Joannis-Cassan, C., Isambert, A., and Raherimandimby, M. (2011). Improvement of the growth of Arthrospira (Spirulina) platensis from Toliara (Madagascar): Effect of agitation, salinity and $\mathrm{CO}_{2}$ addition. Food Bioprod. Process. 89, 209-216. doi: 10.1016/j.fbp.2010.04.009

Ravelonandro, P. H., Ratianarivo, D. H., Joannis-Cassan, C., Isambert, A., and Raherimandimby, M. (2008). Influence of light quality and intensity in the cultivation of Spirulina platensis from Toliara (Madagascar) in a closed system. J. Chem. Technol. Biotechnol. 83, 842-848. doi: 10.1002/jctb.1878

Rechter, S., Konig, T., Auerochs, S., Thulke, S., Walter, H., Dornenburg, H., et al. (2006). Antiviral activity of Arthrospira-derived spirulan-like substances. Antiviral Res. 72, 197-206. doi: 10.1016/j.antiviral.2006.06.004

Riccardi, G., Sora, S., and Ciferri, O. (1981). Production of amino acids by analogresistant mutants of the cyanobacterium Spirulina platensis. J. Bacteriol. 147, 1002-1007.

Riccardi, G., Spra, S., and Ciferri, O. (1982). Characterization of mutants of Spirulina platensis resistant to amino acids analogues. FEMS Microbiol. Lett. 12, 333-336. doi: 10.1111/j.1574-6968.1981.tb07668.x

Riva, P., and Oreal, P. (2013). Anticancer drug and selenium-enriched Spirulina platensis: a new concept for drug delivery and high anti-proliferative activity. Ann. Oncol. 24, i23-i26. doi: 10.1093/annonc/mdt045.13

Roy, K. R., Arunasree, K. M., Reddy, N. P., Dheeraj, B., Reddy, G. V., and Reddanna, P. (2007). Alteration of mitochondrial membrane potential by Spirulina platensis C-phycocyanin induces apoptosis in the doxorubicinresistant human hepatocellular-carcinoma cell line HepG2. Biotechnol. Appl. Biochem. 47, 159-167. doi: 10.1042/BA20060206

Rym, B. D., Nejeh, G., Lamia, T., Ali, Y., Rafika, C., Khemissa, G., et al. (2010). Modeling growth and photosynthetic response in Arthrospira platensis as function of light intensity and glucose concentration using factorial design. $J$. Appl. Phycol. 22, 745-752. doi: 10.1007/s10811-010-9515-9

Saeid, A., Chojnacka, K., Korczynski, M., Korniewicz, D., and Dobrzanski, Z. (2013). Effect on supplementation of Spirulina maxima enriched with $\mathrm{Cu}$ on production performance, metabolical and physiological parameters in fattening pigs. J. Appl. Phycol. 25, 1607-1617. doi: 10.1007/s10811-0139984-8 
Saini, M. K., and Sanyal, S. N. (2014). Piroxicam and c-phycocyanin prevent colon carcinogenesis by inhibition of membrane fluidity and canonical Wnt/ $\beta$ catenin signaling while up-regulating ligand dependent transcription factor PPAR. Biomed. Pharmacother. 68, 537-550. doi: 10.1016/j.biopha.2014.03.007

Saini, M. K., and Sanyal, S. N. (2015). Cell cycle regulation and apoptotic cell death in experimental colon carcinogenesis: intervening with cyclooxygenase- 2 inhibitors. Nutr Cancer. 67, 620-636. doi: 10.1080/01635581.2015.1015743

Samuels, R., Mani, U. V., Iyer, U. M., and Nayak, U. S. (2002). Hypocholesterolemic effect of spirulina in patients with hyperlipidemic nephrotic syndrome. J. Med. Food 5, 91-96. doi: 10.1089/109662002760178177

Sánchez-Luna, L. D., Bezerra, R. P., Matsudo, M. C., Sato, S., Converti, A., and de Carvalho, J. C. (2007). Influence of $\mathrm{pH}$, temperature, and urea molar flowrate on Arthrospira platensis fed-batch cultivation: a kinetic and thermodynamic approach. Biotechnol. Bioeng. 96, 702-711. doi: 10.1002/bit. 21097

Sánchez-Luna, L. D., Converti, A., Tonini, G. C., Sato, S., and de Carvalho, J. (2004). Continuous and pulse feedings of urea as a nitrogen source in fed-batch cultivation of Spirulina platensis. Aquacult. Eng. 31, 237-245. doi: 10.1016/j.aquaeng.2004.04.003

Santhanam, J. S. A. P. (2011). Antipathogenic activity of spirulina powder. Rec. Res. Sci. Technol. 3:4.

Sarada, D. V. L., Kumar, C. S., and Rengasamy, R. (2011). Purified C-phycocyanin from Spirulina platensis (Nordstedt) Geitler: a novel and potent agent against drug resistant bacteria. World J. Microbiol. Biotechnol. 27, 779-783. doi: 10.1007/s11274-010-0516-2

Sarma, A. P., Peter, P., ul Hasan, A., and Murthy, S. D. S. (2010). Effect of photosynthetically active radiation and ultraviolet? on the filamentous structure of the cyanobacterium, Spirulina platensis. Global J. Environ. Res. 4, 54-58.

Savvaidis, I. (1998). Recovery of gold from thiourea solutions using microorganisms. Biometals 11, 145-151. doi: 10.1023/A:1009234113485

Scheldeman, P., Baurain, D., Bouhy, R., Scott, M., Muhling, M., Whitton, B. A., et al. (1999). Arthrospira ('Spirulina') strains from four continents are resolved into only two clusters, based on amplified ribosomal DNA restriction analysis of the internally transcribed spacer. FEMS Microbiol. Lett. 172, 213-222. doi: 10.1111/j.1574-6968.1999.tb13471.x

Schwartz, J., Shklar, G., Reid, S., and Trickler, D. (1988). Prevention of experimental oral cancer by extracts of Spirulina-Dunaliella algae. Nutr. Cancer 11, 127-134. doi: 10.1080/01635588809513979

Senachak, J., Cheevadhanarak, S., and Hongsthong, A. (2015). SpirPro: a Spirulina proteome database and web-based tools for the analysis of protein-protein interactions at the metabolic level in Spirulina (Arthrospira) platensis C1. BMC Bioinformatics 16:233. doi: 10.1186/s12859-015-0676-Z

Shih, P. M., Wu, D., Latifi, A., Axen, S. D., Fewer, D. P., Talla, E., et al. (2013). Improving the coverage of the cyanobacterial phylum using diversitydriven genome sequencing. Proc. Natl. Acad. Sci. U.S.A. 15, 1053-1058. doi: $10.1073 /$ pnas.1217107110

Shimamatsu, H. (2004). Mass production of Spirulina, an edible microalga. Hydrobiologia 512, 39-44. doi: 10.1023/B:HYDR.0000020364.23796.04

Shiraishi, H., and Tabuse, Y. (2013). The AplI restriction-modification system in an edible Cyanobacterium, Arthrospira (Spirulina) platensis NIES-39, recognizes the nucleotide sequence 5'-CTGCAG-3'. Biosci. Biotechnol. Biochem. 77, 782-788. doi: 10.1271/bbb.120919

Singh, A. K., Chakarvathy, D., Singh, T. P. K., and Singh, H. N. (1996). Evidence for a role for l-proline as a salinity protectant in the cyanobacterium Nostoc muscorum. Plant Cell Environ. 19, 490-494. doi: 10.1111/j.1365-3040.1996.tb00342.x

Sinha, R. P., and Häder, D. P. (2002). UV-induced DNA damage and repair, a review. Photochem. Photobiol. Sci. 1, 225-236. doi: 10.1039/b201230h

Song, Q., Shun, T., Peijun, Z., and Tseng, C. K. (1993). Isolation of plasmid from the blue-green alga Spirulina platensis. Chin. J. Oceanol. Limnol. 11, 285-288. doi: $10.1007 / \mathrm{BF} 02850862$

Srivastava, A., Tiwari, R., Srivastava, V., Singh, T. B., and Asthana, R. K. (2015). Fresh water cyanobacteria Geitlerinema sp. CCC728 and Arthrospira sp. CCC729 as an anticancer drug resource. PLoS ONE 10:e0136838. doi: 10.1371/journal.pone.0136838

Steffens, D., Leonardi, D., Soster, P. R., Lersch, M., Rosa, A., Crestani, T., et al. (2014). Development of a new nanofiber scaffold for use with stem cells in a third degree burn animal model. Burns 40, 1650-1660. doi: 10.1016/j.burns.2014.03.008

Steffens, D., Lersch, M., Rosa, A., Scher, C., Crestani, T., Morais, M. G., et al. (2013). A new biomaterial of nanofibers with the microalga spirulina as scaffolds to cultivate with stem cells for use in tissue engineering. J. Biomed. Nanotechnol. 9, 710-718. doi: 10.1166/jbn.2013.1571

Subhashini, J., Mahipal, S. V., Reddy, M. C., Mallikarjuna Reddy, M., Rachamallu, A., and Reddanna, P. (2004). Molecular mechanisms in C-phycocyanin induced apoptosis in human chronic myeloid leukemia cell line-K562. Biochem. Pharmacol. 68, 453-462. doi: 10.1016/j.bcp.2004.02.025

Suganya, K. S., Govindaraju, K., Kumar, V. G., Dhas, T. S., Karthick, V., Singaravelu, G., et al. (2015). Blue green alga mediated synthesis of gold nanoparticles and its antibacterial efficacy against Gram positive organisms. Mater. Sci. Eng. C Mater. Biol. Appl. 47, 351-356. doi: 10.1016/j.msec.2014.11.043

Tambiev, A. K., Vasilieva, S. G., and Lukyanov, A. A. (2011). Manifestation of salt tolerance of Spirulina platensis and Spirulina maxima cyanobacteria of the genus Arthrospira (Spirulina). Moscow Univ. Biol. Sci. Bull. 66, 133-137. doi: 10.3103/S0096392511040079

Taton, A., Grubisic, S., Brambilla, E., De Wit, R., and Wilmotte, A. (2003). Cyanobacterial diversity in natural and artificial microbial mats of Lake Fryxell (McMurdo Dry Valleys, Antarctica): a morphological and molecular approach. Appl. Environ. Microbiol. 69, 5157-5169. doi: 10.1128/AEM.69.9.5157-5169.2003

Tomaselli, L. (1997). "Morphology, ultrastructure and taxonomy," in Spirulina platensis (Arthrospira): Physiology, Cell-Biology and Biotechnology, ed A. Vonshak (London:Taylor \& Francis Ltd), 1-15.

Torres-Duran, P., Ferreira-Hermosillo, A., and Juarez-Oropeza, M. (2007). Antihyperlipidemic and antihypertensive effects of Spirulina maxima in an open sample of mexican population: a preliminary report. Lipids Health Dis. 6, 33. doi: 10.1186/1476-511X-6-33

Toyomizu, M., Sato, K., Taroda, H., Kato, T., and Akiba, Y. (2001b). Effects of dietary spirulina on meat colour in muscle of broiler chickens. Br. Poult. Sci. 42, 197-202. doi: 10.1080/00071660120048447

Toyomizu, M., Suzuki, K., Kawata, Y., Kojima, H., and Akiba, Y. (2001a). Effective transformation of the cyanobacterium Spirulina platensis using electroporation. J. Appl. Phycol. 13, 209-214. doi: 10.1023/A:10111826 13761

Trabelsi, L., Ouada, H. B., Bacha, H., and Ghoul, M. (2009). Combined effect of temperature and light intensity on growth and extracellular polymeric substance production by the cyanobacterium Arthrospira platensis. J. Appl. Phycol. 21, 405-412. doi: 10.1007/s10811-008-9383-8

Trabelsi, L., Ben Ouada, H., Zili, F., Mazhoud, N., and Ammar, J. (2013). Evaluation of Arthrospira platensis extracellular polymeric substances production in photoautotrophic, heterotrophic and mixotrophic conditions. Folia Microbiol. 58, 39-45. doi: 10.1007/s12223-012-0170-1

Travieso, L., Hall, D., O., Rao, K., K., Benitez, F., Sanchez, E., and Borja, R. (2001). A helical tubular photobioreactor producing Spirulina in a semicontinuous mode. Ini. Biodeterior. Biodegrad. 47, 151-155. doi: 10.1016/S0964-8305(01) 00043-9

Tredici, M. R., Papuzzo, T., and Tomaselli, L. (1986). Outdoor mass culture of Spirulina maxima in sea-water. Appl. Microbiol. Biotechnol. 24, 47-50. doi: 10.1007/BF00266284

Vardaka, E., Kormas, K. A., Katsiapi, M., Genitsaris, S., and Moustaka-Gouni, M. (2016). Molecular diversity of bacteria in commercially available "Spirulina" food supplements. Peer J 4:e1610. doi: 10.7717/peerj.1610

Vicat, J. P., Doumnang Mbaigane, J. C., and Bellion, Y. (2014). Contents of macromineral and trace elements in spirulina (Arthrospira platensis) from France, Chad, Togo, Niger, Mali, Burkina-Faso and Central African Republic. C. R. Biol. 337, 44-52. doi: 10.1016/j.crvi.2013.11.004

Volkmann, H., Imianovsky, U., Oliveira, J. L., and Sant'anna, E. S. (2008) Cultivation of Arthrospira (spirulina) platensis in desalinator wastewater and salinated synthetic medium: protein content and amino acid profile. Braz. J. Microbiol. 39, 98-101. doi: 10.1590/S1517-838220080001 000022

Vonshak, A. (1997). Spirulina platensis (Arthrospira): Physiology, Cell-Biology and Biotechnology. London: Taylor \& Francis Ltd. 
Vonshak, A., and Richmond, A. (1988). Mass production of the blue-green alga Spirulina: an overview. Biomass 15, 233-247. doi: 10.1016/0144-4565(88)90059-5

Vonshak, A., Cheung, S. M., and Chen, F. (2000). Mixotrophic growth modifies the response of Spirulina (Arthrospira) platensis (Cyanobacteria) cells to light. J. Phycol. 36, 675-679. doi: 10.1046/j.1529-8817.2000. 99198.x

Vonshak, A., Laorawat, S., Bunnag, B., and Tanticharoen, M. (2014). The effect of light availability on the photosynthetic activity and productivity of outdoor cultures of Arthrospira platensis (Spirulina). J. Appl. Phycol. 26, 1309-1315. doi: 10.1007/s10811-013-0133-1

Waleron, K., Nakonieczna, J., Waleron, M., and Podhajska, A. J. (2006). Restriction-modification systems - 50 years of studies. Biotechnologia 2, 65-88.

Walsby, A. E. (1994). Gas vesicles. Microbiol. Rev. 58, 94-144.

Wang, C. Y., Fu, C. C., and Liu, Y. C. (2007). Effects of using light-emitting diodes on the cultivation of Spirulina platensis. Biochem. Eng. J. 37, 21-25. doi: 10.1016/j.bej.2007.03.004

Wang, H., Yang, Y., Chen, W., Ding, L., Li, P., Zhao, X., et al. (2013). Identification of differentially expressed proteins of Arthrospira (Spirulina) platensis-YZ under salt-stress conditions by proteomics and qRT-PCR analysis. Proteome Sci. 11:6. doi: 10.1186/1477-5956-11-6

Wang, Z. P., and Zhao, Y. (2005). Morphological reversion of Spirulina (Arthrospira) platensis (Cyanophyta): from linear to helical. J. Phycol. 41, 622-628. doi: 10.1111/j.1529-8817.2005.00087.x

Wilson, G. G. (1991). Organization of restriction-modification systems. Nucleic Acids Res. 19, 2539-2566. doi: 10.1093/nar/19.10.2539

Wu, H., Gao, K., Villafañe, V. E., Watanabe, T., and Helbling, E. W. (2005). Effects of solar UV radiation on morphology and photosynthesis of filamentous cyanobacterium Arthrospira platensis. Appl. Environ. Microbiol. 71, 5004-5013. doi: 10.1128/AEM.71.9.5004-5013.2005

Yakoot, M., and Salem, A. (2012). Spirulina platensis versus silymarin in the treatment of chronic hepatitis $\mathrm{C}$ virus infection. A pilot randomized, comparative clinical trial. BMC Gastroenterol. 12:32. doi: 10.1186/1471-230X-12-32

Yang, F., Li, B., Chu, X. M., Lv, C. Y., Xu, Y. J., and Yang, P. (2014). Molecular mechanism of inhibitory effects of C-phycocyanin combined with all-transretinoic acid on the growth of HeLa cells in vitro. Tumour Biol. 35, 5619-5628. doi: 10.1007/s13277-014-1744-0

Yogianti, F., Kunisada, M., Nakano, E., Ono, R., Sakumi, K., Oka, S., et al. (2014). Inhibitory effects of dietary Spirulina platensis on UVB-induced skin inflammatory responses and carcinogenesis. J. Invest. Dermatol. 134, 2610-2619. doi: 10.1038/jid.2014.188

Zahroojian, N., Moravej, H., and Shivazad, M. (2011). Comparison of marine algae (Spirulina platensis) and synthetic pigment in enhancing egg yolk colour of laying hens. Br. Poult. Sci. 52, 584-588. doi: 10.1080/00071668.2011.610779.

Zarrouk, C. (1966). Contribution to the Study of Cyanophyceae: Influence of Various Physical and Chemical Factors on Growth and Photosynthesis of Spirulina maxima (Setch and Gardner) Geitler. Doctoral thesis, University of Paris, Paris.

Zhao, F., Zhang, X., Liang, C., Wu, J., Bao, Q., and Qin, S. (2006). Genome-wide analysis of restriction-modification system in unicellular and filamentous cyanobacteria. Physiol. Genomics 24, 181-190. doi: 10.1152/physiolgenomics.00255.2005

Conflict of Interest Statement: The authors declare that the research was conducted in the absence of any commercial or financial relationships that could be construed as a potential conflict of interest.

Copyright (C) 2017 Furmaniak, Misztak, Franczuk, Wilmotte, Waleron and Waleron. This is an open-access article distributed under the terms of the Creative Commons Attribution License (CC BY). The use, distribution or reproduction in other forums is permitted, provided the original author(s) or licensor are credited and that the original publication in this journal is cited, in accordance with accepted academic practice. No use, distribution or reproduction is permitted which does not comply with these terms. 